\title{
Sting jets in simulations of a real cyclone by two mesoscale models
}

Article

Published Version

Martínez-Alvarado, O., Weidle, F. and Gray, S. L. (2010) Sting jets in simulations of a real cyclone by two mesoscale models. Monthly Weather Review, 138 (11). pp. 4054-4075. ISSN 0027-0644 doi: https://doi.org/10.1175/2010MWR3290.1 Available at https://centaur.reading.ac.uk/17753/

It is advisable to refer to the publisher's version if you intend to cite from the work. See Guidance on citing.

Published version at: http://dx.doi.org/10.1175/2010MWR3290.1

To link to this article DOI: http://dx.doi.org/10.1175/2010MWR3290.1

Publisher: American Meteorological Society

Publisher statement: (C) Copyright 2011 American Meteorological Society (AMS). Permission to use figures, tables, and brief excerpts from this work in scientific and educational works is hereby granted provided that the source is acknowledged. Any use of material in this work that is determined to be "fair use" under Section 107 of the U.S. Copyright Act September 2010 Page 2 or that satisfies the conditions specified in Section 108 of the U.S. Copyright Act (17 USC §108, as revised by P.L. 94-553) does not require the AMS's permission. Republication, systematic reproduction, posting in electronic form, such as on a web site or in a searchable database, or other uses of this material, except as exempted by the above statement, requires written permission or a license from the AMS. Additional details are provided in the AMS Copyright Policy, available on the AMS Web site located at (http://www.ametsoc.org/) or from the AMS at 617227-2425 or copyright@ametsoc.org.

All outputs in CentAUR are protected by Intellectual Property Rights law, 
including copyright law. Copyright and IPR is retained by the creators or other copyright holders. Terms and conditions for use of this material are defined in the End User Agreement.

\section{www.reading.ac.uk/centaur}

\section{CentAUR}

Central Archive at the University of Reading

Reading's research outputs online 


\title{
Sting Jets in Simulations of a Real Cyclone by Two Mesoscale Models
}

\author{
OSCAR MARTÍNEZ-ALVARADO \\ Department of Meteorology, University of Reading, Reading, United Kingdom \\ FLORIAN WEIDLE* \\ Institute for Atmospheric Physics, Johannes Gutenberg-University Mainz, Mainz, Germany \\ SUZANNE L. GRAY \\ Department of Meteorology, University of Reading, Reading, United Kingdom
}

(Manuscript received 24 November 2009, in final form 27 July 2010)

\begin{abstract}
The existence of sting jets as a potential source of damaging surface winds during the passage of extratropical cyclones has recently been recognized. However, there are still very few published studies on the subject. Furthermore, although it is known that other models are capable of reproducing sting jets, in the published literature only one numerical model [the Met Office Unified Model (MetUM)] has been used to numerically analyze these phenomena. This article aims to improve our understanding of the processes that contribute to the development of sting jets and show that model differences affect the evolution of modeled sting jets. A sting jet event during the passage of a cyclone over the United Kingdom on 26 February 2002 has been simulated using two mesoscale models, namely the MetUM and the Consortium for Small Scale Modeling (COSMO) model, to compare their performance. Given the known critical importance of vertical resolution in the simulation of sting jets, the vertical resolution of both models has been enhanced with respect to their operational versions. Both simulations have been verified against surface measurements of maximum gusts, satellite imagery, and Met Office operational synoptic analyses, as well as operational analyses from the ECMWF. It is shown that both models are capable of reproducing sting jets with similar, though not identical, features. Through the comparison of the results from these two models, the relevance of physical mechanisms, such as evaporative cooling and the release of conditional symmetric instability, in the generation and evolution of sting jets is also discussed.
\end{abstract}

\section{Introduction}

The detailed analysis of the Great Storm in southeastern England in October 1987 using both observations (Browning 2004; Browning and Field 2004) and highresolution numerical simulations (Clark et al. 2005) led to the concept of sting jet as a transient, highly localized, lowlevel jet occurring within rapidly deepening extratropical cyclones that develop according to the Shapiro-Keyser

\footnotetext{
* Current affiliation: Central Institute for Meteorology and Geodynamics (ZAMG), Vienna, Austria.

Corresponding author address: Oscar Martínez-Alvarado, Department of Meteorology, University of Reading, Earley Gate, P.O. Box 243, Reading RG6 6BB, United Kingdom.

E-mail: o.martinezalvarado@reading.ac.uk
}

model of cyclogenesis (Shapiro and Keyser 1990). Forecasters' empirical knowledge of the existence of a phenomenon of this type can be traced back as far as the late 1960s (Grønås 1995). However, the concept of sting jets as such is still relatively new. Although there are partial analyses of two other storms over the British Isles (one of which is revisited in the present article) suggesting the presence of sting jets (Browning 2004), the literature on the subject is still sparse. To the authors' knowledge there is only one other sting jet event (during Windstorm Jeanette over the United Kingdom on 27 October 2002) that has been studied in great detail from observational and numerical perspectives (Parton et al. 2009). Moreover, both numerical modeling studies have used the Met Office Unified Model (MetUM) version 5.3. In these studies the vertical resolution of the MetUM was enhanced with respect to that of the operational version. 
This enhancement was necessary to reproduce realistic sting jets, showing that the vertical resolution plays a critical role in a model's ability to simulate sting jet events. More recently, the numerical study of Windstorm Gudrun/Erwin during 7-9 January 2005 has provided further evidence of the importance of sting jets as part of the structure of some extratropical cyclones (Baker 2009). This study was also performed using the MetUM, version 6.1, with enhanced vertical resolution.

Anecdotal evidence indicates that other models apart from the MetUM are capable of producing sting jets. However, it is not known whether there are certain model characteristics, in addition to sufficient vertical resolution, that are required to generate realistic sting jets. The primary objective of this study is to address the question of how model differences affect their ability to simulate sting jets. A second objective of the study is to provide a new case study enabling further investigation of possible mechanisms, such as evaporative cooling and the release of conditional symmetric instability, leading to the development of sting-jet events in the light of the current conceptual model (Clark et al. 2005; reviewed in section 2). To achieve these two objectives, two different limited-area mesoscale models have been used to investigate the passage over the United Kingdom of an explosive cyclone on 26 February 2002 that produced strong winds over Wales and the north of England during the early hours of that day.

The models that have been used are the MetUM version 6.1 and the Consortium for Small Scale Modeling (COSMO) model version 4.0 developed by the Deutscher Wetterdienst (DWD). Both are limited-area models (LAMs) and are used here with comparable horizontal resolutions. The vertical resolution of both models has been enhanced with respect to their operational versions in order to increase their ability to explicitly resolve slantwise convective motion (believed to be important in the generation of sting jets). A more detailed description of the mesoscale models used in this study is given in section 3 . Section 4 gives a description of the methods used to detect and verify the existence of sting jets. Section 5 provides a synoptic and observational background to the case study. The detailed comparison of the predictions of the two mesoscale models is presented in section 6. Finally, a summary and conclusions are given in section 7 .

\section{Conceptual model of sting jets}

Unlike the Norwegian model of cyclogenesis (Bjerknes 1919; Bjerknes and Solberg 1922), the Shapiro-Keyser model (Shapiro and Keyser 1990) is characterized by the development of perpendicular motion of the system's (a)

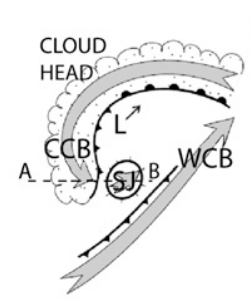

(b)

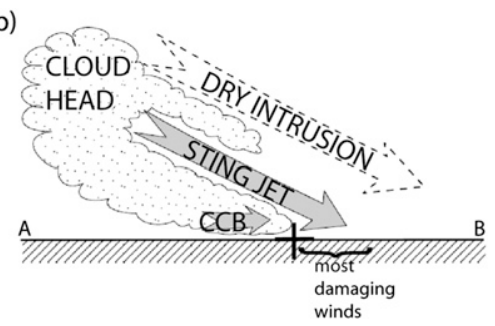

FIG. 1. Conceptual model of stage III in Shapiro-Keyser-type cyclones featuring sting jets. (a) Horizontal structure of systemrelative low-level jets, including the position of the cloud head and surface fronts. Gray arrows show the position of low-level jets. $\mathrm{CCB}$ is the cold conveyor belt, WCB is the warm conveyor belt, SJ is the sting jet, and $\mathrm{L}$ denotes the position of the low pressure center. The thin arrow shows the direction in which the cyclone is traveling. (b) Vertical cross section along $A B$ in (a) showing the relative position of the dry intrusion, the sting jet, and CCB with respect to each other and the region of cloud. [Copyright (2005) Wiley. Used with permission from Clark et al. (2005)].

cold front, relative to its warm front. This motion is the origin of what is known as frontal fracture (Browning et al. 1997; Schultz et al. 1998). The warm front bends back at a later stage giving rise to a secondary cold front, or "bent-back front." This process appears to play an important role in the occurrence of sting jets that develop ahead of the bent-back front within the fractured frontal region (Clark et al. 2005).

The sting jet is distinct from other airstreams featuring in conceptual models of airflow through cyclones, such as the warm and cold conveyor belts (WCB and CCB, respectively; Carlson 1980; Schultz 2001). Both conveyor belts exhibit low-level jet components that, like a sting jet, can be associated with damaging winds during a cyclone's passage. However, their origin, location, and extent are clearly different (Fig. 1a). Also, whereas the conveyor belts have a life period comparable to the duration of the storm itself, a sting jet is a short-lived feature subject to mesoscale processes with a period of duration of the order of hours.

According to the current conceptual model (Browning 2004; Clark et al. 2005), a sting jet corresponds to the descending branches of stacked slantwise circulations within the frontal zone between the bent-back front and the primary cold front, after the frontal fracture has occurred. The slantwise circulations could possibly be due to the release of conditional symmetric instability (CSI; Bennetts and Hoskins 1979; Schultz and Schumacher 1999) in the frontal-fracture region. The sting jet originates within the cloud head, in the midtroposphere, from where it descends (accelerating as it moves) toward the top of the boundary layer (Fig. 1b). The descent is possibly enhanced by evaporative cooling due to precipitation falling into the sting jet from higher clouds. Once the 
sting jet reaches the top of the boundary layer, the sting jet's high momentum can be transferred down through the boundary layer giving rise to strong surface wind gusts. This momentum transfer has been associated with characteristic cloud features observed in the dry slot of the Great Storm in October 1987. These cloud features have been interpreted as the result of boundary layer convergence lines caused by the interaction between multiple sting jets and the boundary layer (Browning and Field 2004).

From a practical point of view, the ability to predict the occurrence of such a phenomenon is important because of the potential loss of life and property damage that could occur as a consequence of the strong winds that a sting jet could generate. For example, strong winds with gusts from 40 to $50 \mathrm{~m} \mathrm{~s}^{-1}$ were attributed to the occurrence of a sting jet during the Great Storm in October 1987 (Browning 2004). Understanding the mechanisms that give rise to sting jets could allow their diagnosis from low-resolution general circulation models or statistical models such as those in use within the insurance/ reinsurance industry (e.g., Keller et al. 2004). Nevertheless, many questions regarding the physical mechanisms behind the development of this phenomenon remain open.

One open question is the importance of the release of CSI in the development of sting jets. Banded structures consistent with the release of CSI within the cloud head have been observed in satellite imagery (Browning 2004) and wind profiler measurements (Parton et al. 2009). Furthermore, numerical simulations have shown the presence of slantwise circulations within the cloud head (Clark et al. 2005), possibly related to the release of CSI (through upward motion) within the same region (Parton et al. 2009). All these observations would support the hypothesis of CSI release playing a role in the development of sting jets (Browning 2004; Clark et al. 2005). Based on this hypothesis, Clark et al. (2005) and Parton et al. (2009) used the MetUM with an enhanced vertical resolution (90 levels in comparison with 38 levels in the equivalent operational version). The vertical resolution enhancement would have enabled the model to resolve CSI-related slantwise circulations with a vertical to horizontal scale ratio of around 1:50 [Clark et al. 2005; also consistent with the resolution recommendations by Persson and Warner $(1991,1993)]$. The vertical resolution was found to be of critical importance for numerical weather prediction (NWP) models to be able to simulate sting jets (Clark et al. 2005). However, the importance of CSI release for the initiation of sting jets is still unclear.

Another open question is the role of evaporative cooling. Using trajectories in the analysis of a sting jet during the October 1987 storm, Clark et al. (2005) found that decreasing potential temperature was accompanied by increasing specific humidity along the trajectories that descended the most. This suggests that evaporative cooling was taking place and might indeed have been the cause of the enhanced descent of these trajectories. Although this observation did not hold for the trajectory ensemble in general, the hypothesis of evaporative cooling was also supported by a faster downstream motion of the sting jet relative to that of air wrapping around the cloud head (Browning 2004). Similarly, trajectories in the upper side of the sting jet in Windstorm Jeanette experienced a decrease in potential temperature while moistening, which was also interpreted as a behavior consistent with evaporation of precipitation from upper levels (Parton et al. 2009). However, with only two case studies in the published literature, there is not yet conclusive evidence linking this process to the evolution of sting jets.

\section{Models}

The MetUM is an operational nonhydrostatic finitedifference model that solves the deep-atmosphere dynamical equations with a semi-implicit, semi-Lagrangian integration scheme (Davies et al. 2005). The model uses Arakawa $\mathrm{C}$ staggering in the horizontal. The vertical coordinate system is terrain following with a hybridheight vertical coordinate and Charney-Phillips staggering. The model can be configured either as a global model or as a LAM with one-way nesting. A rotated horizontal grid is used in the LAM configuration. The model parameterization of physical processes includes longwave and shortwave radiation (Edwards and Slingo 1996), boundary layer mixing (Lock et al. 2000), convection (Gregory and Rowntree 1990), and cloud microphysics and large-scale precipitation (Wilson and Ballard 1999). The large-scale precipitation scheme represents microphysical processes by a single-moment bulk parameterization assuming four phases, namely water vapor, liquid water, ice aggregates, and rain. The particle size distributions of liquid water content, rain, and ice aggregates are specified as gamma distributions, with different parameter values for each type of hydrometeor. Version 6.1 of the MetUM is used here in the North Atlantic European domain configuration. Operationally this was run with $720 \times 432$ grid boxes of $0.11^{\circ}(\sim 12 \mathrm{~km})$ in the horizontal and 38 model levels (lid around $39 \mathrm{~km}$ ); we use the same horizontal grid points and model lid, but with enhanced vertical levels as described below. The currently operational configuration for this domain (version 7.3 of the MetUM) is run with $600 \times 360$ grid points with the same gridbox size in the horizontal, and 70 model levels (lid around $80 \mathrm{~km}$ ). The North Atlantic European 
domain covers nearly all of the North Atlantic and Europe, extending from eastern Canada, and including most of Greenland and the northern part of North Africa (the results shown in this paper are on subsections of this domain).

The COSMO model is a nonhydrostatic fully compressible LAM. This model also uses rotated Arakawa C staggering in the horizontal and a terrain-following, hybrid-height vertical coordinate, but with Lorenz staggering. The time integration is implemented by a modified second-order leapfrog time-split integration scheme (Skamarock and Klemp 1992). The physical parameterizations include subgrid-scale turbulence (Mellor and Yamada 1982), surface layer (Louis 1979), longwave and shortwave radiation (Ritter and Geleyn 1992), convection (Tiedke 1989), and microphysics (Doms et al. 2007). The formation of precipitation is also implemented by a single-moment bulk microphysics parameterization. Unlike the MetUM, the COSMO model simulates four hydrometeor categories: cloud water, cloud ice, rain, and snow. For nonprecipitating hydrometeor categories (cloud ice and water), a monodisperse size distribution is assumed, whereas for precipitating categories (rain and snow) an exponential distribution that stems from fitting to the observed characteristics of raindrops is used (Marshall and Palmer 1948). The COSMO model is run operationally at the DWD at two different resolutions in the horizontal (corresponding to grid boxes of 7 and $2.8 \mathrm{~km}$, respectively), and 40 vertical levels (lid around $24 \mathrm{~km}$ ). In this study we used the COSMO-EU setup, and the DWD resolution, which runs with grid boxes of $0.0625^{\circ}(\sim 7 \mathrm{~km})$ in the horizontal. The COSMO model simulation was performed over a domain with $481 \times 449$ grid points, including most of the North Atlantic and Europe.

Given the critical influence of the vertical resolution on the simulation of sting jets (Clark et al. 2005; Parton et al. 2009), a 76-level version of the MetUM (lid around $39 \mathrm{~km}$ ) and a 56-level version of the COSMO model (lid around $24 \mathrm{~km}$ ) have been used in the simulations. Notice that the 76 levels in this modified version of the MetUM are different from the 70 levels in the current operational version (which extends over twice the atmospheric depth). The additional levels in the MetUM were inserted between the 38 levels used in the operational version 6.1 of this model. The additional levels in the COSMO model were inserted in the lower and midtroposphere between 900 and $600 \mathrm{hPa}$. The additional levels provided the models with midtropospheric vertical spacing between 200 and $370 \mathrm{~m}$ in the MetUM and 120 and $240 \mathrm{~m}$ in the COSMO model [both are comparable to the $240-\mathrm{m}$ vertical spacing in the 90-level model in Clark et al. (2005)]. Comparisons between the models
TABLE 1. MetUM and COSMO model grid parameters.

\begin{tabular}{lll}
\hline \hline & MetUM & COSMO model \\
\hline $\begin{array}{l}\text { Horizontal grid box } \\
\text { Equivalent horizontal }\end{array}$ & $0.11^{\circ}$ & $0.0625^{\circ}$ \\
$\quad$ grid spacing & $12 \mathrm{~km}$ & $7 \mathrm{~km}$ \\
$\begin{array}{l}\text { No. vertical levels (operational) } \\
\text { Midtroposphere vertical }\end{array}$ & 38 & 40 \\
$\quad$ spacing (operational) & $420-740 \mathrm{~m}$ & $230-400 \mathrm{~m}$ \\
$\begin{array}{l}\text { No. vertical levels } \\
\quad \text { (enhanced) }\end{array}$ & 76 & 56 \\
$\begin{array}{l}\text { Midtroposphere vertical } \\
\text { spacing (enhanced) }\end{array}$ & $200-370 \mathrm{~m}$ & $120-240 \mathrm{~m}$ \\
\hline
\end{tabular}

and between their operational and vertically enhanced versions are given in Table 1. Simulations performed with the operational vertical resolution of both models produced storms of similar pressure depth to those performed with vertical resolution enhancements. However, the strongest winds (at $850 \mathrm{hPa}$ ) forecast by the former were restricted to significantly smaller areas than those forecast by the models with improved vertical resolution.

\section{Diagnostic tools}

The detection of sting jets, whether in observational data or in numerical simulations, is not a straightforward procedure, mainly because of their highly localized nature both in space and time. Since a sting jet is expected to occur within the frontal-fracture region, its characteristic horizontal length scale should be of the order of $100 \mathrm{~km}$, which implies a span over about 10 grid points in any horizontal direction.

The potential existence of a sting jet in the models is identified by the computation of surface wind gusts and system-relative wind velocities, as described in sections 4a,b. The positive identification and characterization of sting jets as low-level jets distinct from the WCB and CCB is achieved through a combination of a sting-jet search method at low levels and trajectory analysis (as described in section 4c).

\section{a. Surface wind gusts}

Some evidence for the existence of sting jets can be acquired by the computation of surface wind gusts as a model-derived diagnostic. This allows comparison of model output with surface observations and, hence, serves as part of the validation of the models.

The gust computation in the COSMO model considers two components: convective and turbulent gusts. The maximum near-surface wind gusts (at 10-m height) are computed from the turbulent state of the atmospheric boundary layer by interpolating the wind speed in the lowest model layer (between 0 and $25 \mathrm{~m}$ ) as (Schulz 2008) 


$$
\left|U_{\text {max gust }}\right|=\left|U_{30}\right|+3 \sigma_{C},
$$

where $\sigma_{C}$ is the standard deviation of near-surface wind, diagnosed as (Panofsky and Dutton 1984)

$$
\sigma_{C}=2.4 C_{t}^{1 / 2}\left|U_{\text {lowest }}\right|,
$$

where $U_{30}$ is a model-derived mean wind speed at $30-\mathrm{m}$ height, $C_{t}$ is a turbulent transfer coefficient for momentum, empirically derived from the model variables called "near-surface turbulence" and "convective turbulence," and $U_{\text {lowest }}$ is wind speed on the lowest model layer. The factor 3 in (1) is an empirical value that yields a good comparison between model-derived gusts and observations (Schulz 2008).

In the MetUM, maximum near-surface wind gusts (at 10-m height) were estimated as in Clark et al. (2005):

$$
\left|U_{\text {max gust }}\right|=\left|U_{\text {mean }}\right|+4 \sigma_{U},
$$

where $\left|U_{\text {mean }}\right|$ is the model-derived mean wind speed at 10 -m height, and $\sigma_{U}$ is the standard deviation of nearsurface wind, evaluated in this model as

$$
\sigma_{U}= \begin{cases}u_{*}(12)^{1 / 3} & \text { if } \quad L \geq 0 \\ u_{*}\left[12-0.5\left(z_{i} / L\right)\right]^{1 / 3} & \text { if } \quad L<0\end{cases}
$$

where $u_{*}$ is the friction velocity, $z_{i}$ is the height of the lowest inversion, and $L$ is the Obukhov length. The stability of the boundary layer is considered through $L$, which is negative under unstable conditions so that the ratio of gust to mean wind is greater in unstable conditions. Equation (4) is motivated by an empirical relation based on the assumption that the ratio of the standard deviation of horizontal turbulent velocity components to the friction velocity depends only on the ratio $z_{i} / L$ (Panofsky et al. 1977).

The model gust computations in both models are performed so that they are valid for the previous hour. A factor of 4 in the MetUM and a factor of 3 in the COSMO model are empirical values that have been validated to give a good approximation to observed gusts (Clark et al. 2005; Schulz 2008) but are, nevertheless, uncertain.

\section{b. System-relative wind velocity}

System-relative wind velocity provides a simple method to visualize the different airstreams occurring within an extratropical cyclone at a given level. For example, the $\mathrm{CCB}$ is difficult to identify in the earth-relative winds, but can easily be seen in system-relative winds. This technique has been used before in previous sting-jet studies (Clark et al. 2005; Baker 2009). Its computation requires first an estimation of the velocity of the system as a whole.

Let us assume that there is a reference frame moving at a velocity $\mathbf{V}_{R}$. Wind velocity measured in this reference frame would be given by $\mathbf{V}_{r}=\mathbf{V}-\mathbf{V}_{R}$, where $\mathbf{V}$ is the earth-relative horizontal wind velocity. The velocity of the system $\mathbf{V}_{S}$ is simply defined as the velocity of the reference frame in which the cyclone center appears as a point with zero velocity. For the sake of simplicity we set the reference frame to move at constant velocity, implicitly assuming that the cyclone also moves at constant velocity. This assumption is a good approximation for a restricted time interval, which is nevertheless longer than the period of interest (i.e., a sting-jet time span). Given the presence of baroclinic vertical shear, a reference level above the boundary layer must be chosen. In this study we have chosen $800 \mathrm{hPa}$ as the reference pressure level, but the results are virtually the same for a layer between 900 and $500 \mathrm{hPa}$. Once the velocity of the system has been estimated, the system-relative wind velocity is simply defined as the horizontal wind velocity as measured in the frame of reference traveling at the system's velocity (i.e., $\mathbf{V}_{r}=\mathbf{V}-\mathbf{V}_{S}$ ).

\section{c. Detection of sting jets}

The method used here to identify the presence of sting jets within the output of our numerical simulations consists of three steps. The first step is a gridpoint-by-gridpoint search for regions that feature sting-jet-like characteristics. This is followed by a backward-trajectory analysis, which yields the origin of these regions. Finally, a further filtering of the resulting trajectories was used to retain only those trajectories that started within the cloud head and approximately conserved wet-bulb potential temperature throughout the descent. These steps are now described in detail.

\section{1) STEP 1}

Following the findings by Clark et al. (2005), sting jets were sought in low-level, relatively dry regions of strongly descending winds located within the frontal-fracture region (defined by a band between two wet-bulb potential temperature surfaces). These conditions are expressed mathematically by the following criteria (applied at every grid point):

$|\mathbf{V}|>v_{\text {min }}, \quad w<0, \quad \mathrm{RH}<\mathrm{RH}_{\text {max }}, \quad \theta_{w, \text { min }}<\theta_{w}<\theta_{w, \text { max }}$,

where $|\mathbf{V}|$ is horizontal wind speed, $w$ is vertical velocity, $\mathrm{RH}$ is relative humidity with respect to ice, and $\theta_{w}$ is wetbulb potential temperature. The actual values of the limiting parameters $v_{\text {min }}, \mathrm{RH}_{\max }, \theta_{w, \min }$, and $\theta_{w \text {,max }}$ must be set on a case-by-case basis. 
The criteria given by (5) are expected to be met by a sting jet near the end of its trajectory when it is close to the surface or, at least, has descended from midtropospheric levels toward the top of the boundary layer. Therefore, these criteria were applied at each grid point in a subdomain restricted to the $N$ lowermost pressure levels. For the MetUM, $N$ was set to 15 pressure levels, which corresponds to $650 \mathrm{hPa}$ given a $25-\mathrm{hPa}$ separation between pressure levels starting at $1000 \mathrm{hPa}$. The COSMO model fields were analyzed directly on model levels. Thus, in this case $N$ was set to 30 model levels (in order to obtain an equivalent coverage). Those grid points satisfying (5) were marked as "true"; the rest were marked as "false". Thus, a three-dimensional map for each chosen snapshot (for each hour, in our case) composed of disconnected, individual grid points was obtained. Then, the true grid points were grouped together into clusters (groups of grid points connected horizontally, vertically, and diagonally), yielding a set of three-dimensional localized atmospheric regions where sting jets were likely to be located.

\section{2) STEP 2}

Although the clustered grid points satisfied the stingjet conditions instantaneously toward the end of a sting jet's descent, it was necessary to have information of their recent past to determine whether they had descended from the cloud head approximately conserving $\theta_{w}$, giving them full sting-jet character. For this purpose, the clustered grid points were used as starting points of backward trajectories computed using the scheme of Wernli and Davies (1997). Trajectory analysis has also been used in previous sting-jet studies (Clark et al. 2005; Parton et al. 2009).

\section{3) STEP 3}

Once trajectories had been determined, $\theta_{w}$ was computed along them. We are interested in air parcels that start in the cloud head ( $\mathrm{RH}>80 \%)$ and remain between the $\theta_{w}$ surfaces constituting the boundaries of the frontalfracture region throughout the descent. These boundaries were subjectively determined based on $\theta_{w}$ contours at a level $(825 \mathrm{hPa})$ just above the boundary layer. Thus, any trajectory which fell outside the interval $\theta_{w \text {,min }}<\theta_{w}<$ $\theta_{w, \max }$ at any time during the analysis period was filtered out.

Knowing the positions of the clusters at earlier times also enabled the reconstruction of the history of any variable of interest. Apart from $\theta_{w}$ and $\mathrm{RH}$, we looked at horizontal wind speed, vertical velocity, potential temperature, and moist potential vorticity (MPV) to characterize the dynamical and thermodynamical evolution of the sting jets. MPV has been computed according to its definition in isobaric coordinates MPV $=-g \boldsymbol{\nabla} \times$ $\mathbf{V} \cdot \nabla \theta_{e}$, where $g$ is the acceleration due to gravity, $\mathbf{V}$ is horizontal wind velocity, and $\theta_{e}$ is equivalent potential temperature. There is still a long-standing debate on whether geostrophic or full winds should be used to compute MPV for the assessment of the presence of moist symmetric instability (Schultz and Schumacher 1999; Gray and Thorpe 2001; Novak et al. 2004, 2006, 2008; Schultz and Knox 2007). Some authors have argued that full wind is expected to be more representative than geostrophic wind in curved-flow environments (Novak et al. 2004, 2006, 2008) or when the basic state is evolving (and therefore out of thermal wind balance; Gray and Thorpe 2001). Both characteristics are found in the frontal-fracture region. Therefore, full winds have been used to compute MPV in this study. However, we recognize that the debate is not closed yet and further research into this matter is still needed.

\section{Case study: Description and synoptic overview}

Measurements from the Mesosphere-StratosphereTroposphere (MST) radar at Aberystwyth, United Kingdom (Vaughan 2002) can be used to identify wind patterns that could be linked to the passage of sting jets over that site (Parton et al. 2010). By compiling a climatology comprising MST radar measurements from 1998 to 2004, Parton et al. (2010) found 9 events that could be classified as sting jets. One of the most prominent of such events took place during the passage of a cyclone between 25 February and 26 February 2002, that originated in the central Atlantic and reached the United Kingdom around 0000 UTC 26 February 2002 (G. A. Parton 2008, personal communication). The strongest winds detected by the MST radar occurred between 0100 and 0700 UTC 26 February 2002, as the parent cyclone went through stage II and III of the Shapiro-Keyser model of cyclogenesis (Shapiro and Keyser 1990). Browning (2004) has also identified this storm as a potential sting-jet bearer, based on the observed presence of multiple slantwise circulations within the cloud head by the MST radar at Aberystwyth (Fig. 5 in Browning 2004, and related discussion therein).

\section{a. Initial and boundary conditions for numerical simulations}

Both models were initialized using the global operational analysis from the European Centre for MediumRange Weather Forecasts (ECMWF) for 1200 UTC 25 February 2002 (grid spacing of $0.5^{\circ}, 60$ vertical levels), corresponding to a lead time in the forecasts of $12-18 \mathrm{~h}$.

For the MetUM, hourly lateral boundary conditions (LBCs) were obtained by nesting the North Atlantic 
European domain in the operational global domain with $432 \times 325$ grid points (approximately equivalent to grid boxes of $60 \mathrm{~km}$ in the extratropics) and 38 vertical levels. The ECMWF analysis was interpolated onto the global model resolution before running the simulation that produced both the initial conditions and the required LBCs for the mesoscale runs. For the COSMO model, the ECMWF initial conditions were interpolated onto the model grid to produce the initial conditions. Six-hourly ECMWF analyses were interpolated onto the model grid to produce the required LBCs.

When the MetUM was initialized at an earlier time (0600 UTC 25 February 2002), it produced a slightly deeper system $(966 \mathrm{hPa}$ rather than $968 \mathrm{hPa}$ ) with slightly stronger winds at $850 \mathrm{hPa}\left(36 \mathrm{~m} \mathrm{~s}^{-1}\right.$ rather than $\left.34 \mathrm{~m} \mathrm{~s}^{-1}\right)$ than the cyclone in the 1200 UTC forecast. In contrast, when the COSMO model was initialized at 0600 UTC, it was unable to reproduce the development of the storm. A different COSMO model run over a larger domain, starting at 0000 UTC 25 February 2002, produced a storm, albeit weaker than that presented in this article. This appears to be indicative of sensitivity to the method used to generate LBCs, and is also a sign of the difficulty of modeling the development of severe cyclones in general.

\section{b. Synoptic context and validation of the models}

Figure 2 shows the minimum sea level pressure of the cyclone every $6 \mathrm{~h}$ along its track, according to 6-hourly Met Office operational synoptic analyses of observational data (ASXX charts; Dominy 2006) and 6-hourly ECMWF operational analyses over the United Kingdom. The central pressure in the Met Office analyses dropped $31 \mathrm{hPa}$ in $24 \mathrm{~h}$ from $996 \mathrm{hPa}$ at 1200 UTC 25 February 2002 to $965 \mathrm{hPa}$ at 1200 UTC 26 February 2002. According to the ECMWF analyses, the central pressure dropped $28 \mathrm{hPa}$ from $994 \mathrm{hPa}$ over the same period. Although the pressure drop in the ECMWF analyses is not as large as in the Met Office analyses, in both cases the cyclone satisfies the criteria for explosively deepening extratropical cyclones (Sanders and Gyakum 1980). The largest difference in central pressure between Met Office and ECMWF analyses (of approximately $7 \mathrm{hPa}$ ) occurs at 0000 UTC 26 February 2002 when the ECMWF analysis displays a value of $976 \mathrm{hPa}$ while the Met Office analysis displays a value of $969 \mathrm{hPa}$. Moreover, there is a noticeable difference in the position of the cyclone in Met Office and ECMWF analyses, ranging from about $20 \mathrm{~km}$ (at 0600 UTC 26 February 2002) to about $220 \mathrm{~km}$ (at 1800 UTC 25 February 2002). The dissimilarities between ECMWF and Met Office analyses just described give an indication of the degree of uncertainty associated with the passage of this cyclone. They also highlight limitations of operational NWP

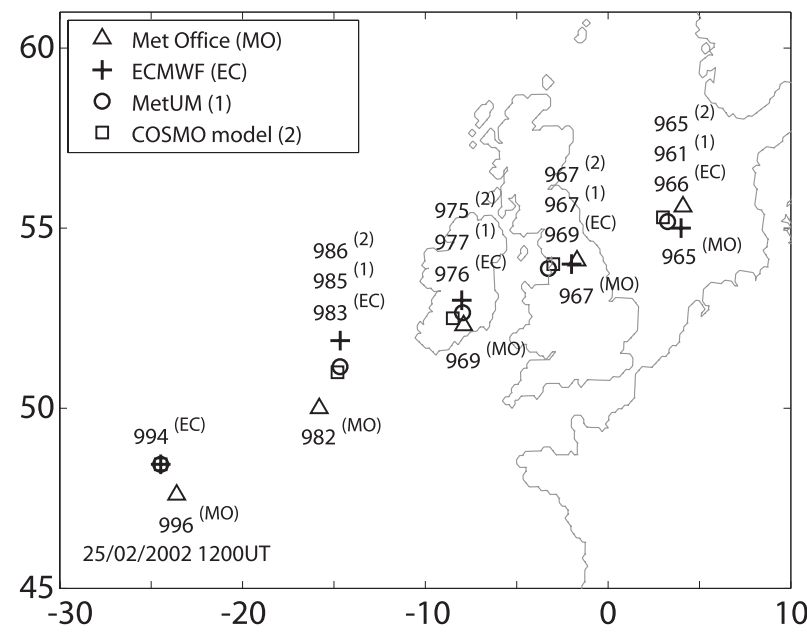

FIG. 2. Cyclone track following pressure minima according to ECMWF operational analyses (EC), Met Office ASXX charts (MO), MetUM forecast (1), and COSMO model forecast (2). The separation between marks is $6 \mathrm{~h}$ starting at 1200 UTC 25 Feb 2002. The quoted numbers are mean sea level pressure $(\mathrm{hPa})$.

models in the prediction of rapidly developing cyclonic systems.

Figure 2 also shows the tracks of the cyclone as forecast by the MetUM and the COSMO model in this study. It shows that both models forecast very similar positions for the cyclone's center throughout the 24-h simulation, although both forecast cyclones were slightly behind that in the ECMWF analyses. The cyclone's depth, on the other hand, was handled differently by each model. Whereas the COSMO model yielded a similar deepening rate [29 $\mathrm{hPa}(24 \mathrm{~h})^{-1}$ ] to the ECMWF analysis, the MetUM simulation yielded a more rapid one $\left[33 \mathrm{hPa}(24 \mathrm{~h})^{-1}\right]$, in particular during the last 6 forecast hours. Despite these differences in the details between analyses and simulations, the cyclone tracks and depths predicted by the MetUM and the COSMO model can be regarded as within a reasonable margin of error of the analyzed ones, especially when considering that the models were allowed to run with no data assimilation implemented during the integrations (other than the initialization and generation of LBCs). Considering the period between 0030 and 1200 UTC 26 February 2002 in the MetUM simulation, the storm traveled with a mean speed of $20.9 \mathrm{~m} \mathrm{~s}^{-1}$ from $250^{\circ}$ (calculated as described in section $4 \mathrm{~b})$. This velocity was also appropriate for the COSMO model simulation and used for the calculation of systemrelative velocities in both models.

The passage of a previous cyclone makes it difficult to identify the different stages in the Shapiro-Keyser model (Shapiro and Keyser 1990) for the case study here. Nevertheless, based on satellite imagery (Fig. 3) and 

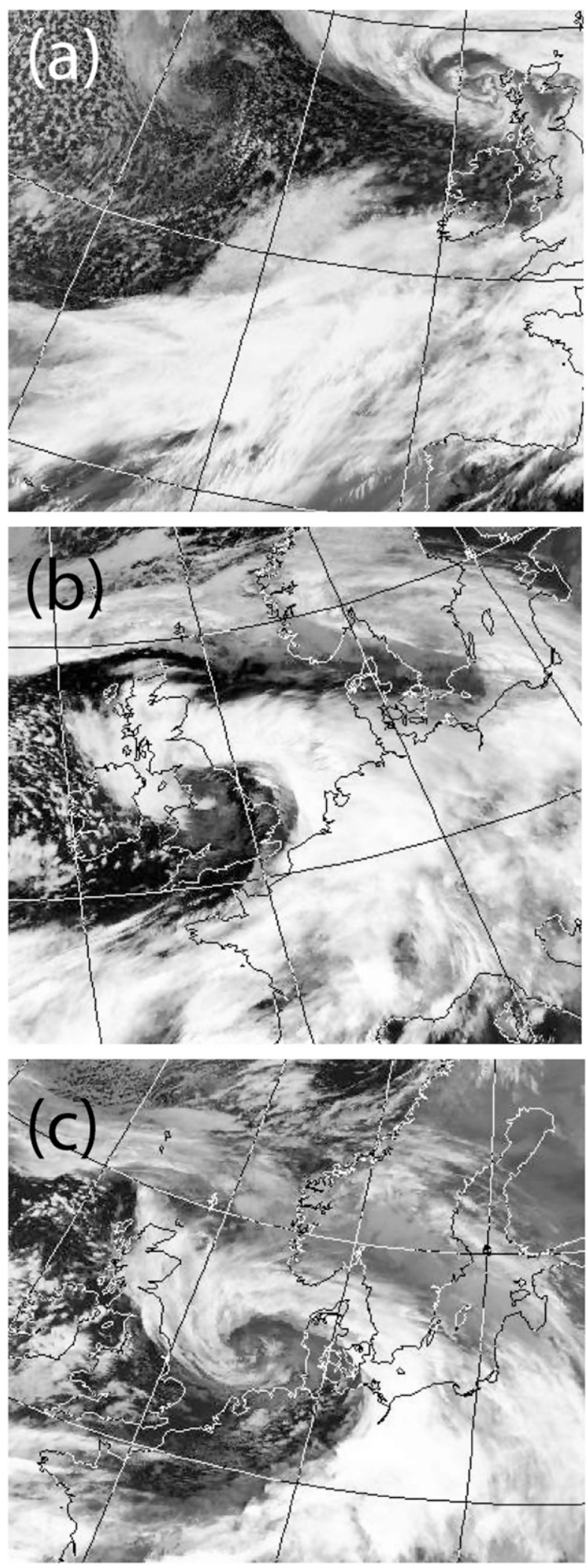

FIG. 3. Thermal infrared (11.5-12.5 $\mu \mathrm{m})$ images from the AVHRR instrument on board the GOES-12 satellite at (a) 1440 UTC 25 Feb 2002, (b) 0518 UTC 26 Feb 2002, and (c) 1248 UTC 26 Feb 2002 (courtesy of Dundee Satellite Receiving Station). information from Met Office ASXX charts and ECMWF operational analyses (Fig. 4), a fairly complete picture of the evolution of the system can be obtained. Stage I (incipient frontal cyclone) began around 1200 UTC 25 February 2002 (and possibly before). Figure 3a shows that, at 1440 UTC, the cloud head had emerged from the polar front cloud band. The system stayed in this stage for approximately 10-12 h. Figure 4a shows the ECMWF analysis fields at the end of stage I at 0000 UTC 26 February 2002. However, the ASXX chart for this time (Fig. 4d) shows an occluded front that might indicate (under the Shapiro-Keyser model of cyclogenesis) that stage II (frontal fracture) had already occurred. Notice that this is the time of maximum discrepancy in central pressure between analyses (Fig. 2). A rapidly developing bent-back front marked the onset of stage III (bent-back front and frontal T-bone) at approximately 0300 UTC 26 February 2002. Figure 3b shows the cyclone at this stage at 0518 UTC 26 February 2002, when the cloud head bending around the bent-back front and the dry intrusion can be clearly seen. The bent-back front was still present at 0600 UTC 26 February 2002, as shown by the ECMWF analysis (Fig. 4b) and the corresponding ASXX chart (Fig. 4e). The cloud head continued to wrap around the cyclone center with the warm seclusion appearing at approximately 1100 UTC 26 February 2002, indicating that the cyclone had reached stage IV (warm-core frontal seclusion, see Figs. $3 c$ and 4c,f).

\section{Case study: Mesoscale analysis}

The observations from the MST radar $\left(52.4^{\circ} \mathrm{N}, 4.0^{\circ} \mathrm{W}\right)$ were compared to MetUM output for the grid point located at $52.0^{\circ} \mathrm{N}, 4.3^{\circ} \mathrm{W}$ (not shown in figures). This grid point was not the nearest grid point to the MST radar site, but the one that produced a height-time wind profile as similar as possible to that produced using MST radar observations during the same time interval. A comparison between the wind speed derived from measurements and that derived from MetUM output shows that the upper-level jet strength is around $60 \mathrm{~m} \mathrm{~s}^{-1}$ both in the model and in observations, although the jet in the model is higher by about $1 \mathrm{~km}$ than that in radar data. The tropospheric wind enhancement due to the passage of the front over the MST radar is in very good agreement in vertical position, magnitude, and timing (between 0100 and 0200 UTC). Moreover, the model shows the signature of slantwise circulations at the right time with respect to the passage of the frontal edge (between 0300 and 0500 UTC), although the magnitude of these circulations is less than that observed by the MST radar and the phasing is slightly different $( \pm 1 \mathrm{~h})$. Similar conclusions can be drawn for the COSMO model. These results 

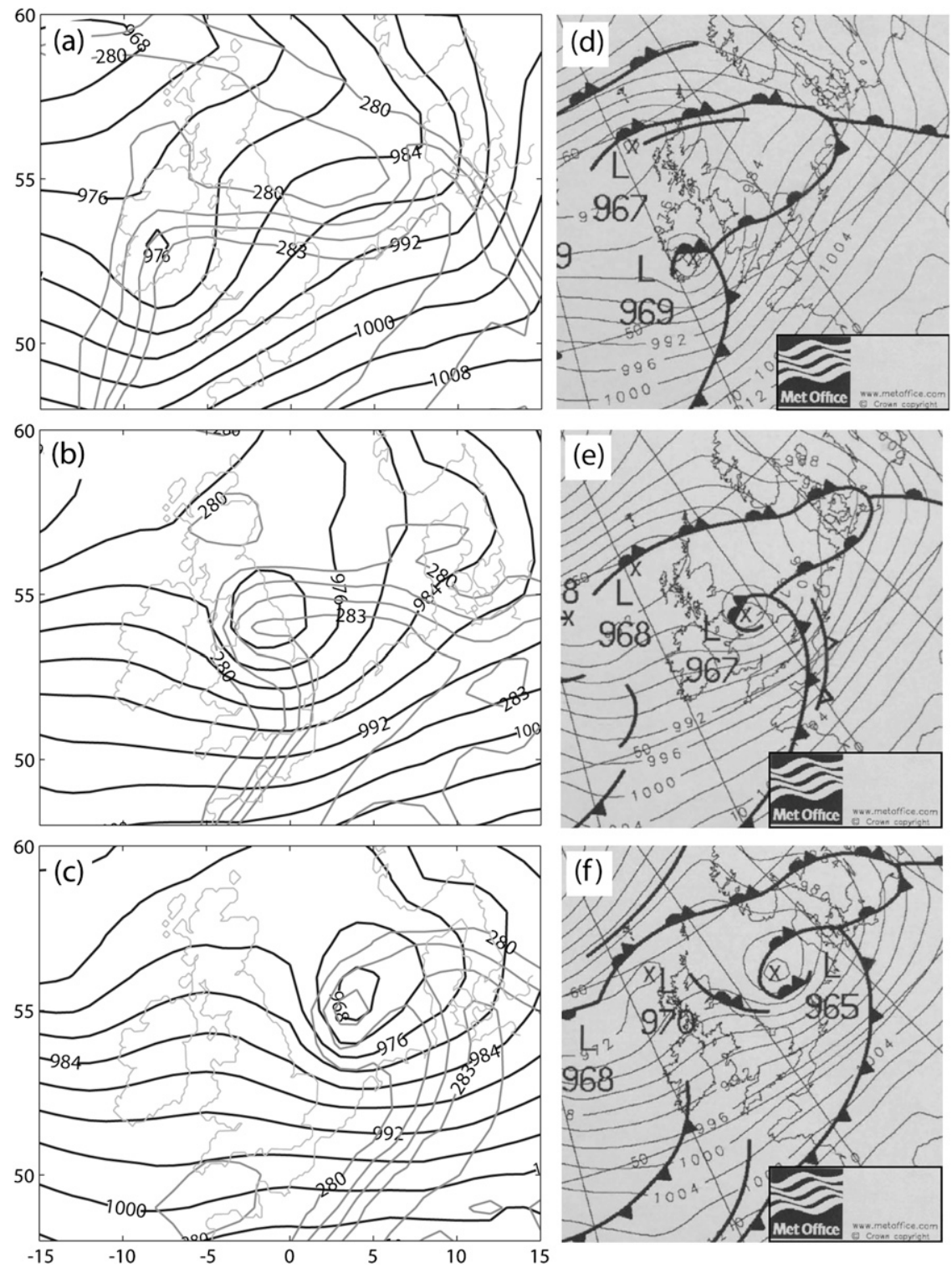

FIG. 4. Mean sea level pressure (black) and $\theta_{w}$ at $850 \mathrm{hPa}$ (from 280 to $283 \mathrm{~K}$, contour interval $=1 \mathrm{~K}$, gray) from the (a)-(c) ECMWF operational analyses and (d)-(f) Met Office ASXX charts at (a),(d) 0000 UTC 26 Feb 2002; (b),(e) 0600 UTC 26 Feb 2002; and (c),(f) 1200 UTC 26 Feb 2002.

indicate that the models are doing a good job in simulating the cyclone's mesoscale structure, but there are errors in terms of position and timing. (N.B. The sting jet discussed in the rest of this article occurred about 3 hours after these slantwise circulations in the model output and observed by the MST radar.)

\section{a. Low-level wind structure}

The passage of the cyclone over the United Kingdom gave rise to strong surface wind speeds and wind gusts, which were recorded by the Met Office Integrated Data
Archive System (MIDAS) Land Surface observation stations (available online at http://badc.nerc.ac.uk/data/ ukmo-midas). These records show that the highest gusts were detected over two different regions at two different time intervals during the early morning of 26 February 2002. Stations over western parts of southern England and Wales reported gusts in the range of $25-30 \mathrm{~m} \mathrm{~s}^{-1}$ between 0300 and 0400 UTC (Fig. 5a), whereas stations in a band southeastward from the north of Wales and from northwestern England to East Anglia and Lincolnshire reported gusts in the range of $25-35 \mathrm{~m} \mathrm{~s}^{-1}$ 

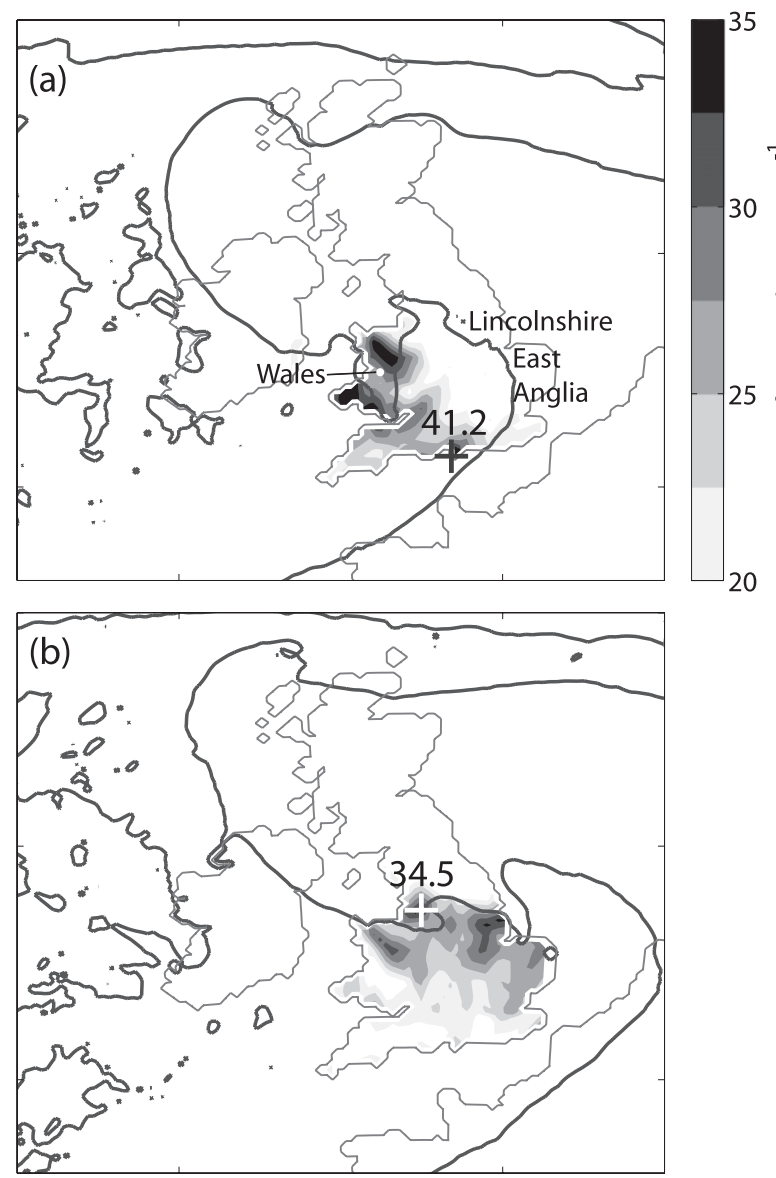

FIG. 5. Gusts observed on 26 Feb 2002 at (a) 0300-0400 and (b) 0600-0700 UTC. The cross and the number near it indicate the position and the magnitude $\left(\mathrm{m} \mathrm{s}^{-1}\right)$ of the highest gust recorded at the time. The heavy black line represents the edge of the cloud determined as the $200 \mathrm{~W} \mathrm{~m}^{-2}$ contour of outgoing longwave radiation at the time as predicted by the MetUM.

between 0600 and 0700 UTC (Fig. 5b). Notice that winds over these regions, and especially over the north of Wales, are also enhanced by high topography and coastal exposure. The strong wind gusts over Wales between 0300 and 0400 UTC occurred at the same time as the slantwise circulations in MST radar data (and model output) described in the previous paragraph. This region was not chosen for further analysis as model fields did not show a clearly differentiated sting jet at this time. However, the surface and MST radar observations suggest that a sting jet could have occurred.

Figure 6 shows the earth-relative wind speed maps at $850 \mathrm{hPa}$ (above the top of the boundary layer, which was at $\sim 900 \mathrm{hPa}$ ) at $0700 \mathrm{UTC}$ as forecast by both the MetUM (Fig. 6a) and the COSMO model (Fig. 6b). This time was chosen based on the following two criteria. First, the MIDAS land surface observation stations showed strong gusts over the north of England at this time.
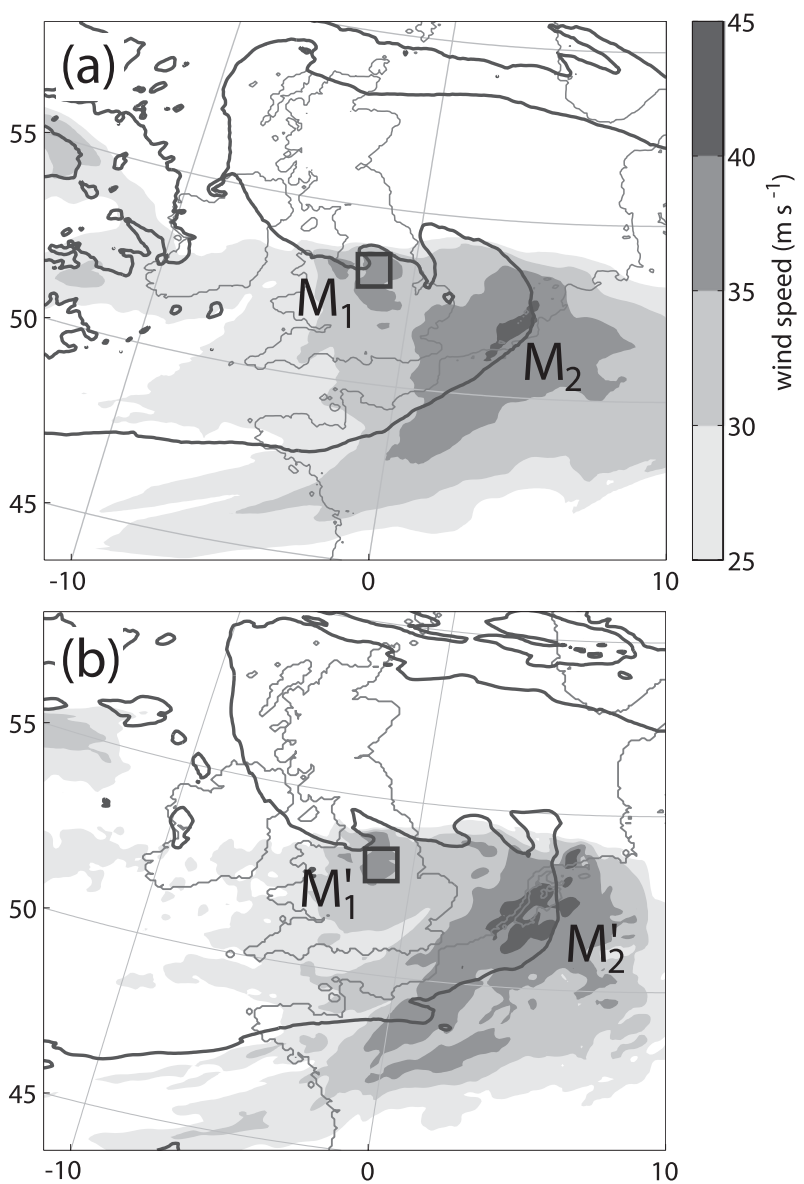

FIG. 6. The earth-relative wind speed $\left(\mathrm{m} \mathrm{s}^{-1}\right)$ at $850 \mathrm{hPa}$ as forecast by (a) the MetUM and (b) the COSMO model at 0700 UTC 26 Feb 2002. The heavy black line represents the edge of the cloud determined as (a) the $200 \mathrm{~W} \mathrm{~m}^{-2}$ contour of outgoing longwave radiation as predicted by the MetUM and (b) the 250-K contour of brightness temperature as forecast by the COSMO model. The rectangle marked in both panels encloses the region where a sting jet was detected using the method described in section $4 \mathrm{c}$.

Second, it was the first hour at which both the MetUM and the COSMO model showed a clearly differentiated local wind maximum over this region. Two wind speed local maxima are shown in each map, one over northern England $\left(\mathrm{M}_{1}\right.$ and $\left.\mathrm{M}_{1}^{\prime}\right)$ and another one off the coast of the Netherlands $\left(\mathrm{M}_{2}\right.$ and $\left.\mathrm{M}_{2}^{\prime}\right)$. The strong wind regions, labeled $\mathrm{M}_{1}$ and $\mathrm{M}_{1}^{\prime}$, are approximately located over the position of the stations recording maximum wind gusts between 0600 and 0700 UTC (Fig. 5b). Given the location of the strong wind regions labeled $\mathrm{M}_{2}$ and $\mathrm{M}_{2}^{\prime}$ relative to cloud-covered areas, close to the southern cloud band (cf. Fig. 3b), an association between these winds and the WCB low-level jet component can also be drawn.

Figure 7 shows maps of maximum near-surface wind gusts (estimated by the method described in section 4a), 

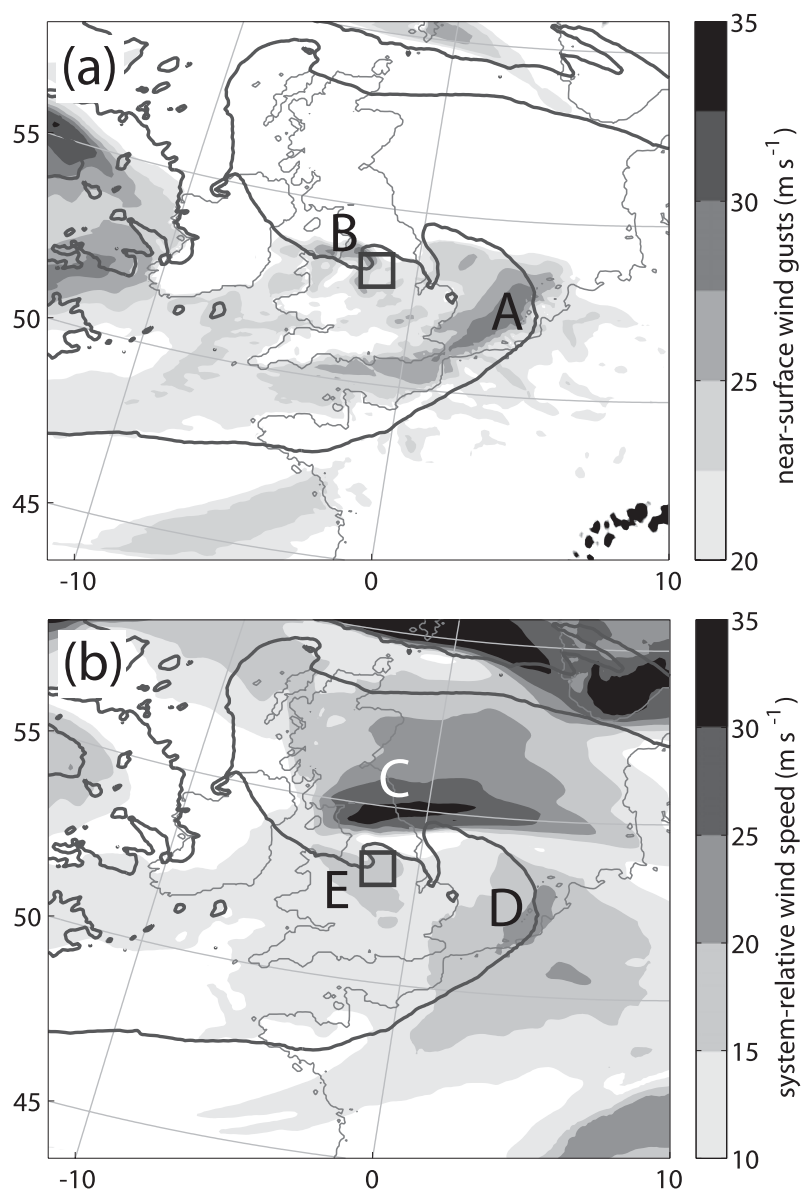

FIG. 7. (a) Maximum near-surface wind gusts $\left(\mathrm{m} \mathrm{s}^{-1}\right)$ and (b) system-relative wind speed $\left(\mathrm{m} \mathrm{s}^{-1}\right)$ at $850 \mathrm{hPa}$ as forecast by the MetUM at 0700 UTC 26 Feb 2002. The heavy black line represents the edge of the cloud (determined as the $200 \mathrm{~W} \mathrm{~m}^{-2}$ contour of outgoing longwave radiation as predicted by the MetUM). The gray rectangle marked in both panels encloses the region where a sting jet was detected using the method described in section $4 \mathrm{c}$. The wind speed maxima labeled $\mathrm{A}-\mathrm{E}$ are discussed in the text.

and system-relative wind at $850 \mathrm{hPa}$ for the MetUM forecast between 0600 and 0700 UTC. The MetUM places gusts over similar regions to those observed over land, namely, north of Wales and the north of England. However, the gusts in the model are at least $5 \mathrm{~m} \mathrm{~s}^{-1}$ weaker than those observed. Moreover, whereas the regions of strongest gusts were observed over the north of Wales, Lincolnshire, and East Anglia, the model predicts only a small region of maximal gusts over the north of England, with two weaker maxima over central England. Thus, there are two regions where gusts (associated with the cyclone) are most intense. Region A is located off the Dutch coast and is, therefore, possibly related to $\mathrm{M}_{2}$ in Fig. 6a. Region B is located over the north of England and Wales and is, therefore, possibly related to the strong gusts recorded by the MIDAS stations at that time (Fig. $5 b)$ and to $M_{1}$ in Fig. 6a.

There are three separate areas of strong system-relative wind speed, above $15 \mathrm{~m} \mathrm{~s}^{-1}$, around the cyclone's center above the boundary layer (Fig. 7b). Region $\mathrm{C}$ is linked to circulations wrapping around the cyclone's center within the warm frontal region. The colder portion of region $\mathrm{C}$ is part of an incipient CCB (see also section 6c). Given its location, close to the southern cloud band, region $\mathrm{D}$ is related to the WCB. The third region of high systemrelative winds, region $\mathrm{E}$, appears in the frontal-fracture region, at and beyond the tip of the cloud head. Comparing Figs. $7 \mathrm{a}$ and $7 \mathrm{~b}$, the coincidence between the regions $\mathrm{A}$ and $\mathrm{B}$ of strong surface wind gusts and the location of regions $\mathrm{D}$ and $\mathrm{E}$ of strong system-relative winds at $850 \mathrm{hPa}$ is clear. Region C in Fig. 7a is not correlated with a region of strong surface gusts because, relative to the system, it was directed westward, while the system itself was traveling eastward, a combination that resulted in weak earth-relative velocities.

Figure 8 shows maximum near-surface wind gusts and system-relative wind speed at $850 \mathrm{hPa}$, as estimated from the COSMO model forecast at 0700 UTC. Comparing Figs. $8 \mathrm{a}$ and $7 \mathrm{a}$ the locations of strong surface wind gusts are similar in both models. As in the MetUM forecast, there were two main regions of strong system-relative wind gusts. Region A1 was located over the WCB lowlevel jet component. Region B1 was located in the frontalfracture zone. Compared to the MetUM, the COSMO model seemed to better simulate the observed gust intensity with maximum wind gusts higher than $32 \mathrm{~m} \mathrm{~s}^{-1}$, although the regions of strong gusts are wider than those observed.

Unlike the MetUM forecast, the map of system-relative wind speed from the COSMO model (Fig. 8b) exhibits only two clearly differentiated regions of high wind intensity, above $15 \mathrm{~m} \mathrm{~s}^{-1}$. Region C1 (analogous to region C in Fig. 7b) lies in the expected location of the CCB's lowlevel jet component. Analogous to Region D in Fig. 7b, region D1 corresponds to the low-level jet component of the WCB. Region E1 could be interpreted as an extension of region $\mathrm{C} 1$. However, it lies in the frontal-fracture region at and beyond the tip of the cloud head possibly at the CCB's exit zone. Moreover, region $\mathrm{C} 1$ is characterized by system-relative wind speed above $20 \mathrm{~m} \mathrm{~s}^{-1}$, whereas region E1 is characterized by lower systemrelative wind speed (between 15 and $20 \mathrm{~m} \mathrm{~s}^{-1}$ ). Thus, region E1 in Fig. 8b can also be interpreted as analogous to region E in Fig. $7 b$.

Although the magnitude of model-derived wind gusts tends to be underestimated relative to observations (especially in the MetUM), the location of regions B (Fig. 7a) and B1 (Fig. 8a) of strong wind gusts are in good 

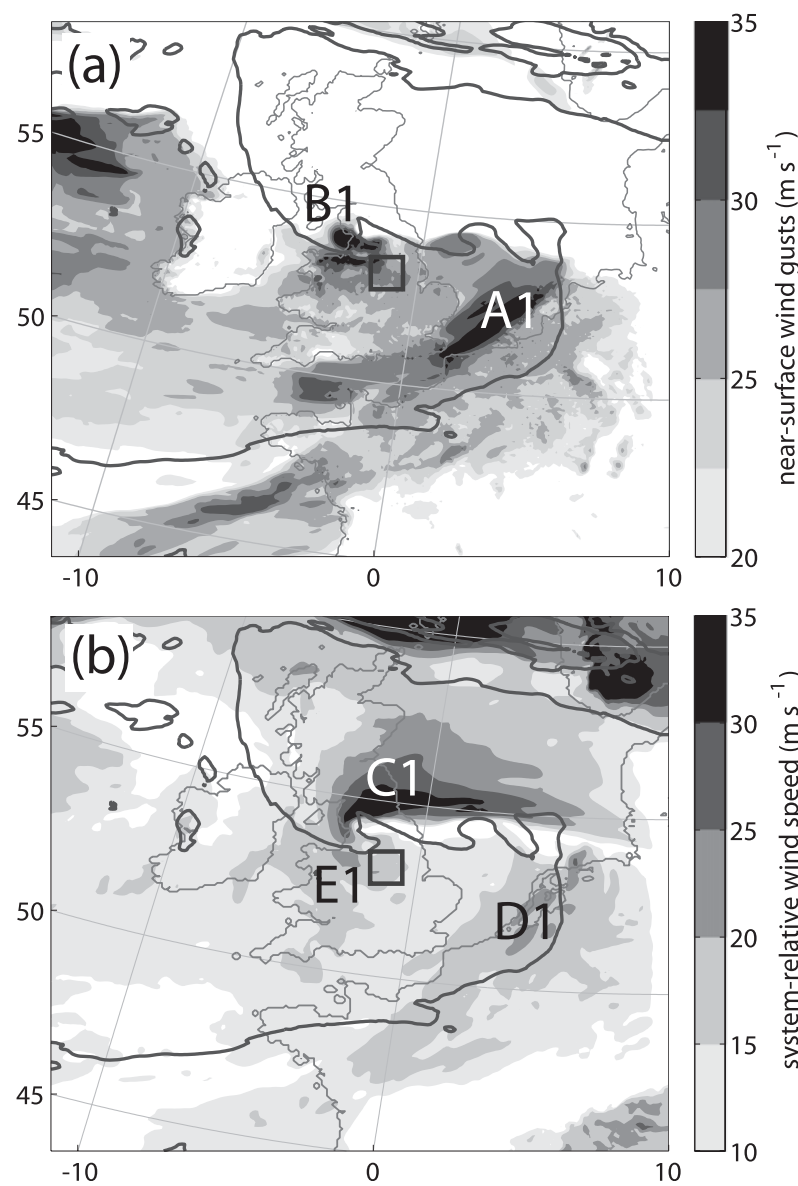

FIG. 8. As in Fig. 7, but for the COSMO model. The heavy black line represents the edge of the cloud (determined as the $250-\mathrm{K}$ contour of brightness temperature as forecast by the COSMO model). (a),(b) The gray rectangle encloses the region where a sting jet was detected using the method described in section $4 \mathrm{c}$. The wind speed maxima labeled A1-E1 are discussed in the text.

agreement with observations. These regions are forecast at the time (during stage II of the Shapiro-Keyser evolution) and locations (in the frontal-fracture region) where a sting jet would be expected, according to the conceptual model of Clark et al. (2005).

\section{b. Identification of sting jets}

The detection method explained in section $4 \mathrm{c}$, with parameter values as shown in Table 2, was applied to hourly instantaneous fields from 0500 to 0900 UTC 26 February 2002. These times were chosen based on the location of strong wind gusts with respect to the cloud head during that interval, as shown by the MIDAS observation stations (Fig. 5b) and satellite imagery (Fig. $3 \mathrm{~b}$ ), as well as the earth-relative wind speed at $850 \mathrm{hPa}$ from the models (Fig. 6). Clusters with sting-jet characteristics were found throughout this period, but were
TABLE 2. Parameter values for the location of sting jets.

\begin{tabular}{lcc}
\hline \hline Parameter & MetUM & COSMO model \\
\hline$v_{\min }\left(\mathrm{m} \mathrm{s}^{-1}\right)$ & 35 & 35 \\
$\mathrm{RH}_{\max }(\%)$ & 80 & 80 \\
$\theta_{w, \min }(\mathrm{K})$ & 280 & 279 \\
$\theta_{w, \max }(\mathrm{K})$ & 282 & 281 \\
\hline
\end{tabular}

most prominent at $0700 \mathrm{UTC}$. In addition to the sting jet identified at that time, the COSMO model showed a low-level jet with sting-jet characteristics at 1100 UTC: wind velocities in excess of $48 \mathrm{~m} \mathrm{~s}^{-1}$, RH below $80 \%$, and negative vertical velocity. In contrast, the MetUM did not show signs of the presence of this jet. The following analysis and discussion refers only to the sting jet at 0700 UTC.

The identified clusters were traced back in time to determine their positions and the values of several variables at earlier times. The backward trajectories were computed using the output from the models every $30 \mathrm{~min}$ from 0700 to 0100 UTC 26 February 2002 and filtered to retain only trajectories for which $\theta_{w \text {,min }}<\theta_{w}<\theta_{w \text {,max }}$ throughout (according to the values given in Table 2) with a starting $\mathrm{RH}>80 \%$, to ensure that these trajectories departed from the cloud head region. Notice that the limiting values of $\theta_{w}$ for the COSMO model are $1 \mathrm{~K}$ lower than those for the MetUM; slightly different values were appropriate for each model after the rest of the criteria were satisfied. Once every condition was satisfied, the set of trajectories that remained was labeled as a sting jet.

The position of the sting jet at 0700 UTC 26 February 2002 (gray box in Figs. 7 and 8) is similar in both models. According to the MetUM, its center is located at $53.3^{\circ} \mathrm{N}$, $1.6^{\circ} \mathrm{W}$, whereas the COSMO model predicts its center at $53.2^{\circ} \mathrm{N}, 1.2^{\circ} \mathrm{W}$. In the vertical direction, the sting jet in the MetUM forecast extended from 800 to $650 \mathrm{hPa}$, whereas in the COSMO model forecast it extended from 809 to $669 \mathrm{hPa}$ (recall that MetUM output was analyzed on pressure levels whereas COSMO model output was analyzed directly on model levels). The sting jets were found to the south of the cyclone's center, which at that time was located at about $54.1^{\circ} \mathrm{N}, 2.3^{\circ} \mathrm{W}$. The location of the sting jet, exiting the cloud head within the fractured frontal zone, is in good agreement with the conceptual model discussed in section 2 .

Figure 9 shows the position of the sting jet at two different times from the trajectories produced by the MetUM. Figure 9a shows the position of the identified sting jet at 0300 UTC 26 February 2002. At this time the system has begun the transition from stage II into stage III of the Shapiro-Keyser model (Shapiro and Keyser 1990). The frontal fracture is evident from the widening in the separation between isotherms to the southwest of the 

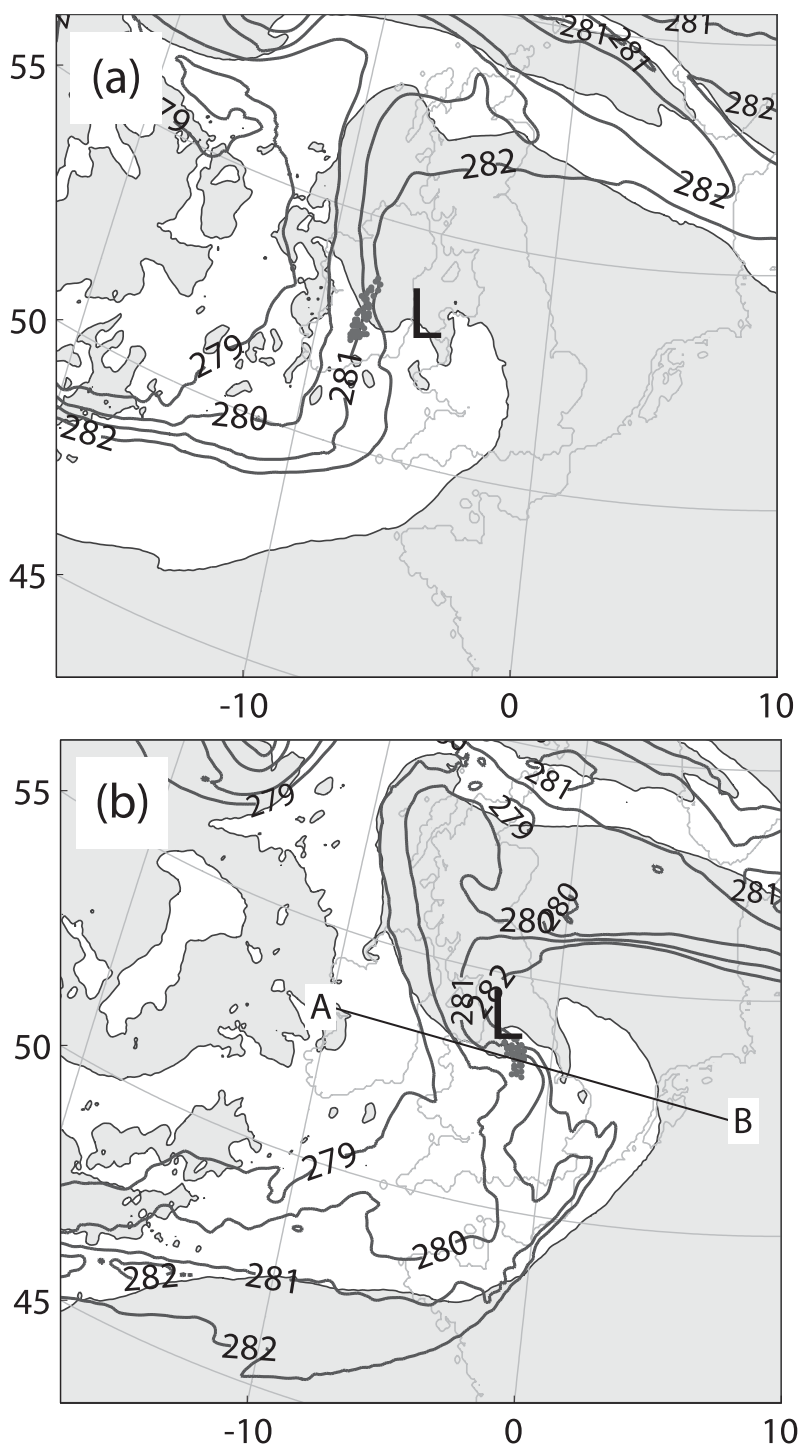

FIG. 9. Horizontal projection of the position of the sting jet (gray dots) according to the MetUM at (a) 0300 and (b) 0700 UTC $26 \mathrm{Feb}$ 2002. The frames also show lines of constant $\theta_{w}$ at the mean level of the sting jet [heavy lines: (a) 575 and (b) $700 \mathrm{hPa}$ ] from 279 to $282 \mathrm{~K}$ with a contour interval of $1 \mathrm{~K}$. The shading represents the area covered by cloud (as determined in Fig. 7). Large Ls indicate the positions of the surface cyclone centers. The line in (b) marks the location of the vertical cross section in Fig. 11a.

cyclone's center. The sting jet is located to the west of the low pressure center, just at the edge of the cloud head and within the frontal-fracture region at a mean pressure level of approximately $575 \mathrm{hPa}$. Four hours later (0700 UTC 26 February 2002), the bent-back front is clearly visible as well as the cloud head (Fig. 9b). By this time, the sting jet has descended more than $100 \mathrm{hPa}$ on average with respect to its position at 0300 UTC 26 February 2002 and is located at an approximate pressure level of $700 \mathrm{hPa}$. This is the lowest level reached by
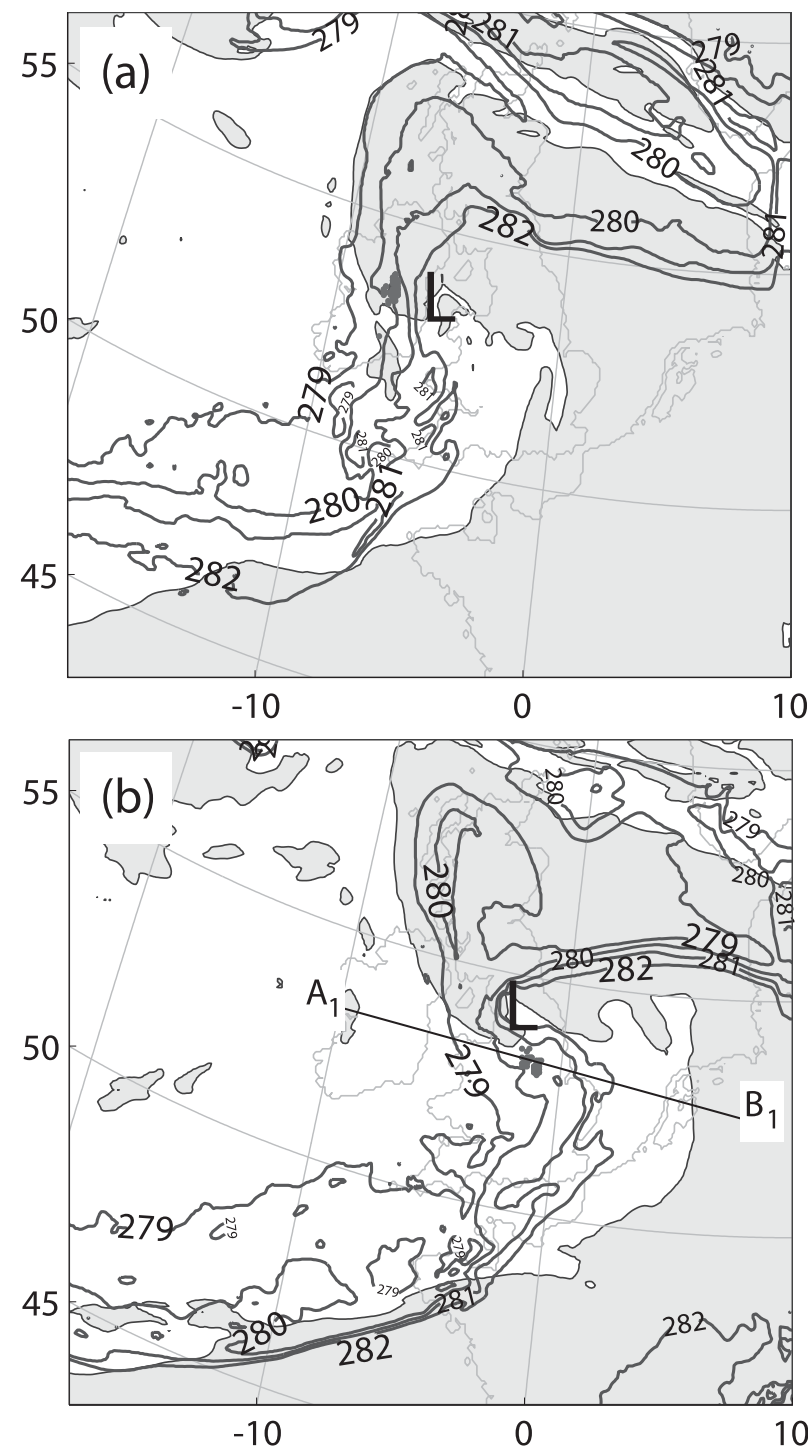

FIG. 10. As in Fig. 9, but according to the COSMO model. The frames also show lines of constant $\theta_{w}$ at the mean level of the sting jet [heavy lines: (a) 675 and (b) $775 \mathrm{hPa}$ ] from 279 to $282 \mathrm{~K}$ with a contour interval of $1 \mathrm{~K}$. The shading represents the area covered by cloud (as determined in Fig. 8). The line in (b) marks the location of the vertical cross section in Fig. 11b.

the center of the sting jet according to the MetUM. Considering the core of the jet, represented by those trajectories within one standard deviation of pressure in the trajectory ensemble, the lowest level reached by the jet is $750 \mathrm{hPa}$ (although there were air parcels that went down to $800 \mathrm{hPa}$ ).

Figure 10 is analogous to Fig. 9 for the identified sting jet simulated by the COSMO model. At 0300 UTC 26 February 2002, the mean position of the sting jet in the COSMO model (Fig. 10a) is slightly to the northeast 
of that in the MetUM forecast. At 0700 UTC 26 February 2002 (Fig. 10b) it is located in dry air, away from the edge of the cloud head. The sting jet in the COSMO model forecast is always below that in the MetUM. This will be discussed in section $6 \mathrm{~d}$, where backward trajectories are analyzed.

\section{c. Frontal-fracture structure}

Figure 11 shows two cross sections along lines $\mathrm{AB}$ and $A_{1} B_{1}$ in Figs. $9 b$ and $10 b$, respectively. These sections were chosen to show the three low-level jets; that is, $\mathrm{CCB}$, sting jet and WCB (left to right), and the structure of the frontal-fracture zone at the time when the sting jet was identified. The two frames show contours of the earth-relative horizontal wind speed and vertical velocity to indicate descending regions of strong wind, $\mathrm{RH}$ to represent the position of the cloud, $\theta_{w}$ to show the frontal-fracture structure, and potential vorticity (PV) to mark the position of the tropopause and, hence, the dry intrusion. The position of the identified portion of the sting jets is indicated by the black dots near the middle of both figures.

Even though Figs. 11a,b are not expected to perfectly match each other, the pictures from both models have similar characteristics. High towers of saturated air, which form part of the WCB, can be seen to the east of the vertical sections. The tower in the MetUM forecast reaches higher altitudes (up to $225 \mathrm{hPa}$ ) than that in the COSMO model, which barely reaches $275 \mathrm{hPa}$. Consistent with this, the tropopause (2-PVU surface, 1 PVU = $1 \mathrm{~K} \mathrm{~kg}^{-1} \mathrm{~m}^{2} \mathrm{~s}^{-1}$ ) is higher in the MetUM forecast than in the COSMO model one. The low-level jet component of the WCB can be seen at the base of this feature between 900 and $800 \mathrm{hPa}$. This is clearly related to the region of high surface wind gusts, which appeared in Fig. 7a (Fig. 8a), marked A and D (A1 and D1) in the MetUM (COSMO model). Immediately to the west of the WCB, the intrusion of dry air from the upper troposphere/lower stratosphere is collocated with a tropopause fold, as diagnosed from the 2-PVU surface. This fold reaches levels as low as $600 \mathrm{hPa}$ in the MetUM, whereas in the COSMO model it only goes down to about $500 \mathrm{hPa}$.

The end of a sting-jet region is characterized by strong descent and RH below $80 \%$. Since the method used to identify potential sting jets is restricted to a low-level search, the full vertical extension of the sting jet is not completely marked by the black dots. Indeed, Fig. 11a suggests that the sting jet extends farther up to levels as high as $550 \mathrm{hPa}$ in the MetUM. The region of strongest winds (greater than $38 \mathrm{~m} \mathrm{~s}^{-1}$ ) and the region of maximum descent rate are coincident at a pressure level around
$650 \mathrm{hPa}$. This region of coincidence can be considered as the core of the sting jet. A sting-jet core is not as apparent in the COSMO model as it is in the MetUM, although descending regions of strong horizontal wind speed $(|\mathbf{V}|>$ $35 \mathrm{~m} \mathrm{~s}^{-1}$ ) can still be found at levels as high as $600 \mathrm{hPa}$ (Fig. 11b).

The descent of sting jets shares similarities with the process of formation of a split cold front (Browning and Monk 1982). As in that process, descending air with low$\theta_{w}$ overruns high- $\theta_{w}$ air. As a result, localized regions of potential instability are generated. Unlike the process described in Browning and Monk (1982), the descending air is not part of the dry intrusion, but air exiting and descending from the cloud head. The formation of a split cold front can be seen in both panels of Fig. 11, at the lower part of the leading edge of the respective sting-jet cores. The split cold front is thus formed at different pressure levels in each model. In the MetUM it is located approximately at $700 \mathrm{hPa}\left(0.6^{\circ} \mathrm{W}\right)$, whereas in the COSMO model it occurs around $800 \mathrm{hPa}\left(0^{\circ}\right)$.

Both the MetUM and the COSMO model show another region of strong winds directly beneath the core of the sting jet. It consists of moist air $(\mathrm{RH}>80 \%)$ and winds of more than $37 \mathrm{~m} \mathrm{~s}^{-1}$ with $\theta_{w}$ within the same range as the sting jet. Backward trajectories for the MetUM forecast were used to determine the origin of this low-level jet (not shown in figures). The trajectories were traced back for $6 \mathrm{~h}$ (i.e., to 0100 UTC) from a box between $2.5^{\circ}$ and $1.1^{\circ} \mathrm{W}$ in longitude, $52.8^{\circ}$ and $53.8^{\circ} \mathrm{N}$ in latitude, and 900 and $800 \mathrm{hPa}$ in pressure. The trajectory analysis showed that this jet evolved as a low-level frontal circulation (within the frontal-fracture region), starting to the north of the cyclone center and wrapping around this to end up beneath the sting jet at the time shown in Fig. 11. Moreover, the trajectory analysis suggests that this frontal circulation accelerated suddenly around the time when the sting jet was reaching its lowest level. We hypothesize that this sudden acceleration was the result of momentum transfer from the sting jet toward the frontal circulation. The momentum transfer could have been enabled by convective overturning due to potential instability below the sting-jet core $\left(\partial \theta_{w} / \partial z<0\right)$. However, further analysis is required to decide the validity of this hypothesis. The presence of low-level frontal circulations would prevent sting-jet air from directly reaching the top of the boundary layer. This kind of sting-jet evolution is different from that described by the current conceptual model (Clark et al. 2005), in which the sting jet reaches the top of the boundary layer with subsequent mass and momentum transfer down to the surface.

Another jet $\left(|\mathbf{V}|>35 \mathrm{~m} \mathrm{~s}^{-1}\right)$ below $800 \mathrm{hPa}$ appears to the west of the sting jet (and low-level frontal circulation) in both panels of Fig. 11 (although in the COSMO model 

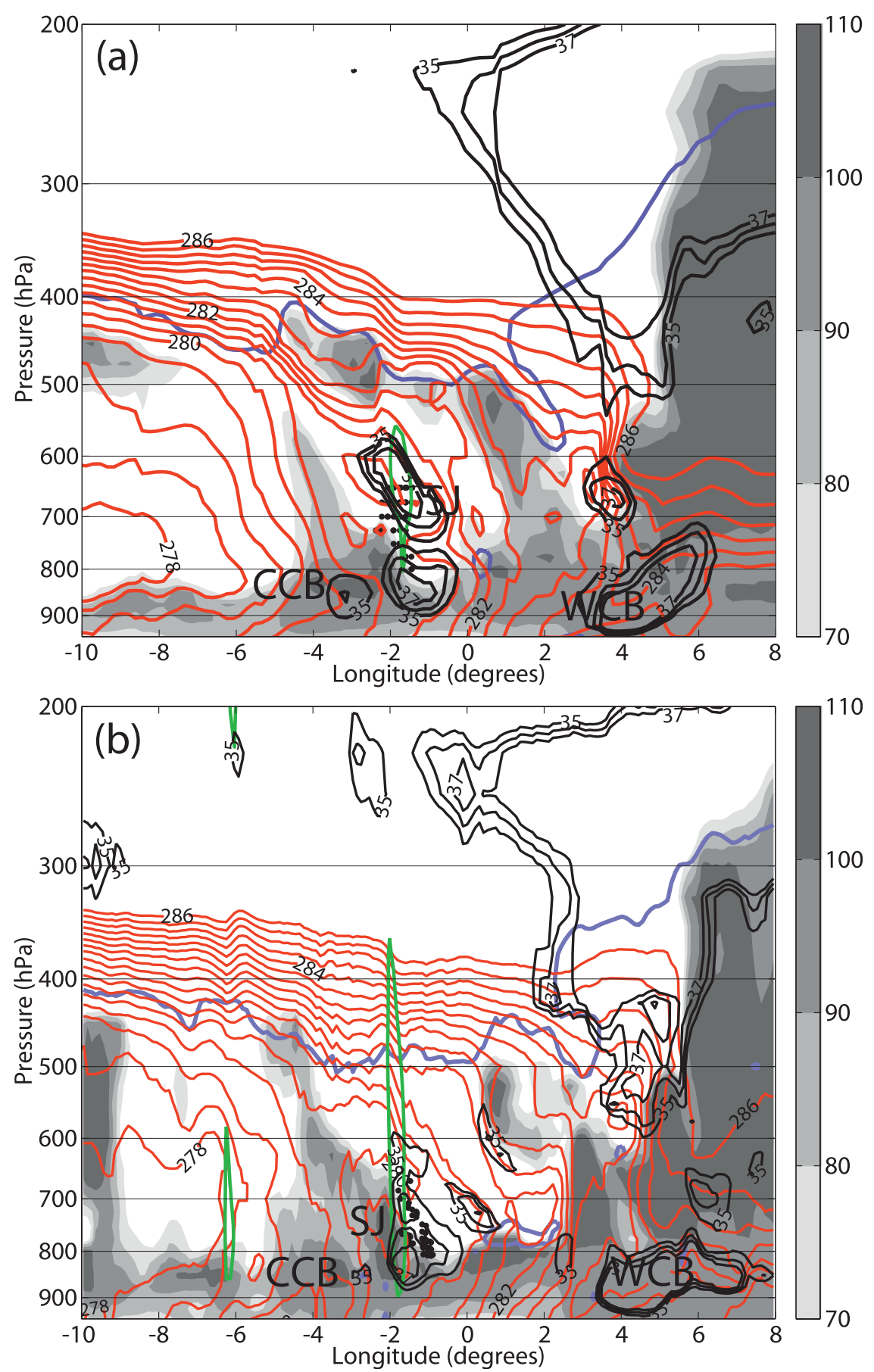

FIG. 11. Vertical cross sections along lines (a) $\mathrm{AB}$ in Fig. $9 \mathrm{~b}$ (MetUM) and (b) $\mathrm{A}_{1} \mathrm{~B}_{1}$ in Fig. 10b (COSMO model) showing RH with respect to ice (grayscale shades, $\%$ ), $\theta_{w}$ isolines between 278 and $286 \mathrm{~K}$ (red contours), the earth-relative horizontal wind speed (black contours at 35, 36, and $37 \mathrm{~m} \mathrm{~s}^{-1}$ ), a vertical velocity isoline for $w=-0.3 \mathrm{~m} \mathrm{~s}^{-1}$ (green contour), and a PV isoline for PV $=2$ PVU (blue contour). The projection of the trajectories constituting the identified sting jet in each case is represented by black dots. 

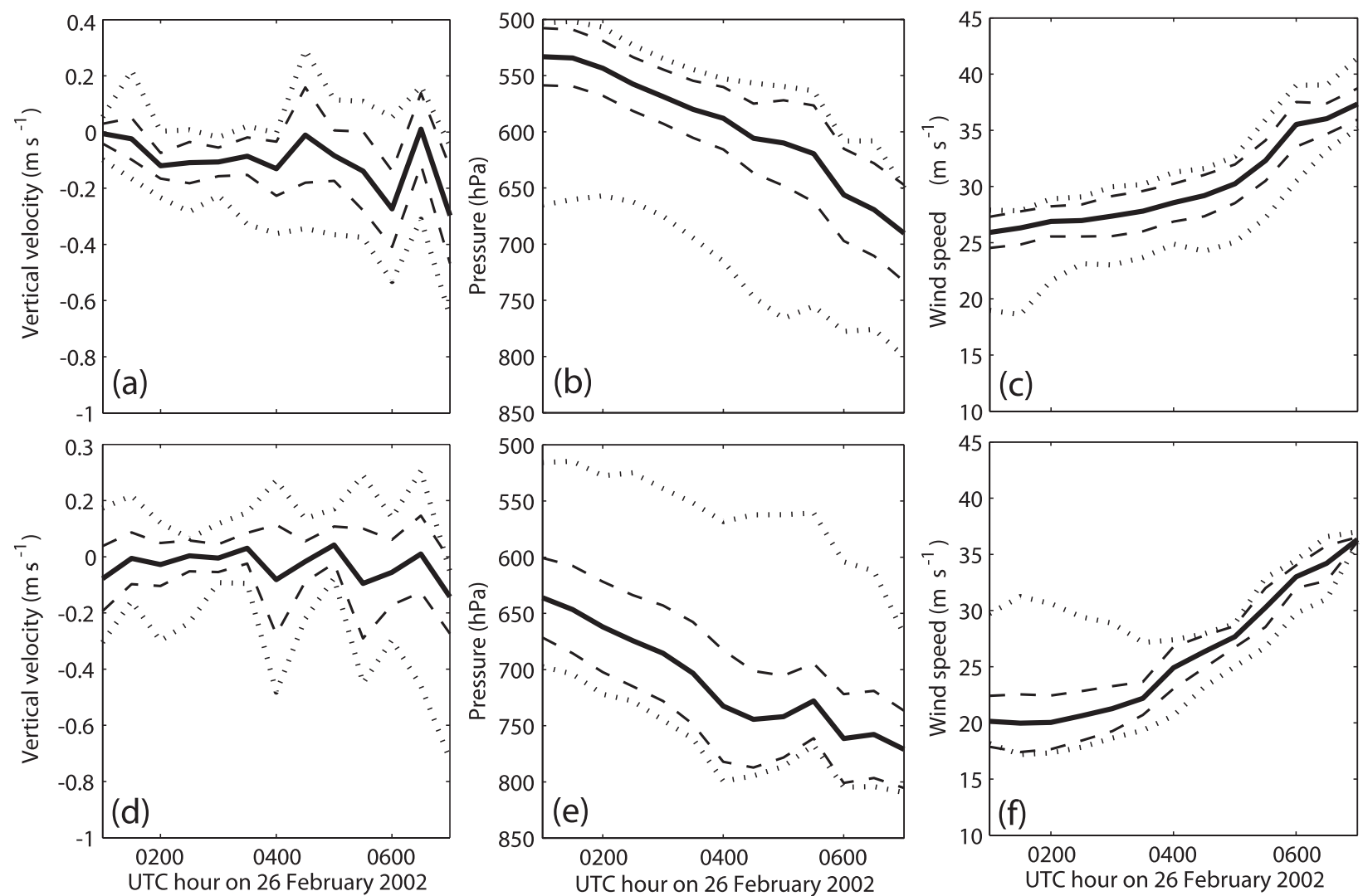

FIG. 12. Time series along the trajectories for (a)-(c) the MetUM and (d)-(f) the COSMO model showing mean values (solid), mean values $\pm 1 \sigma$ (dashed), and instantaneous maxima and minima (dotted) of (a),(d) $w$; (b), (e) pressure; and (c),(f) $|\mathbf{V}|$.

it is represented by a much smaller region). This jet is located in a region of moist air ( $\mathrm{RH}>80 \%)$, and is characterized by lower $\theta_{w}$ values than the sting jet $\left(280 \mathrm{~K}<\theta_{w}<\right.$ $280.5 \mathrm{~K}$ for the MetUM; $279.5 \mathrm{~K}<\theta_{w}<280 \mathrm{~K}$ for the COSMO model). Jets with similar characteristics were identified as the CCB in the studies of the October 1987 Great Storm (Clark et al. 2005) and Windstorm Jeanette (Parton et al. 2009). Forward trajectories for the MetUM show that this jet is indeed part of the CCB, which is not yet wrapped around the cyclone center. It wrapped around the cyclone center around 1100 UTC, with horizontal wind speed greater than $40 \mathrm{~m} \mathrm{~s}^{-1}$ over the North Sea.

\section{d. Evolution of variables along trajectories}

Figures 12,13,14a-b, and 15 show the evolution of the mean, standard deviation and instantaneous minimum and maximum values of several variables along the trajectories described by the sting jets in both models. The maximum and minimum values form an envelope for the ensemble of trajectories and do not necessarily represent a particular trajectory.
The sting jet in the MetUM descended consistently throughout the analyzed period (Fig. 12a). Very few trajectories have positive vertical velocity during the first $3 \mathrm{~h}$ (from 0100 to 0400 UTC). There is an increase in the standard deviation after this period, possibly due to mixing of sting-jet air and air in low-level circulations, such as the low-level jet discussed in section 6c. In contrast, the sting jet in the COSMO model exhibits a vacillating descent with short intervals of positive mean vertical velocity (Fig. 12d). As a result, the sting jet in the MetUM descends more on average than that in the COSMO model. Nevertheless, the sting jet in the MetUM is at all times at lower pressures than its counterpart in the COSMO model (Figs. 12b,e). This is also consistent with the sting jet in the MetUM presenting larger values of $\theta_{w}$ than that in the COSMO model by approximately $1 \mathrm{~K}$. While descending, both jets accelerate horizontally, reaching more than $35 \mathrm{~m} \mathrm{~s}^{-1}$ at the end of the analyzed period (Figs. 12c,f), despite starting at slightly different horizontal speeds ( $26 \mathrm{~m} \mathrm{~s}^{-1}$ in the MetUM; $20 \mathrm{~m} \mathrm{~s}^{-1}$ in the COSMO model).

The sting jet accelerates as the cyclone central pressure deepens markedly. This could be an indication that 

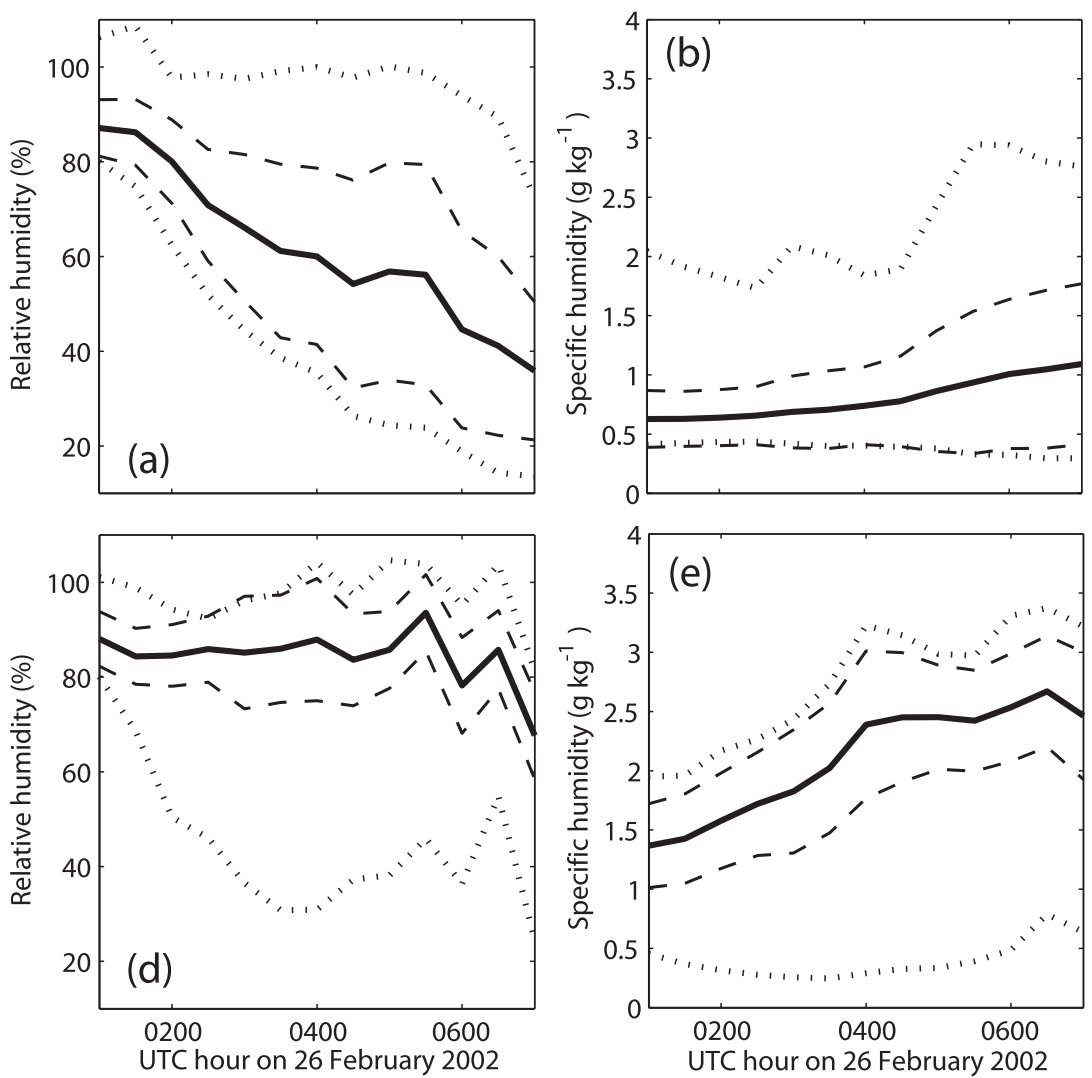
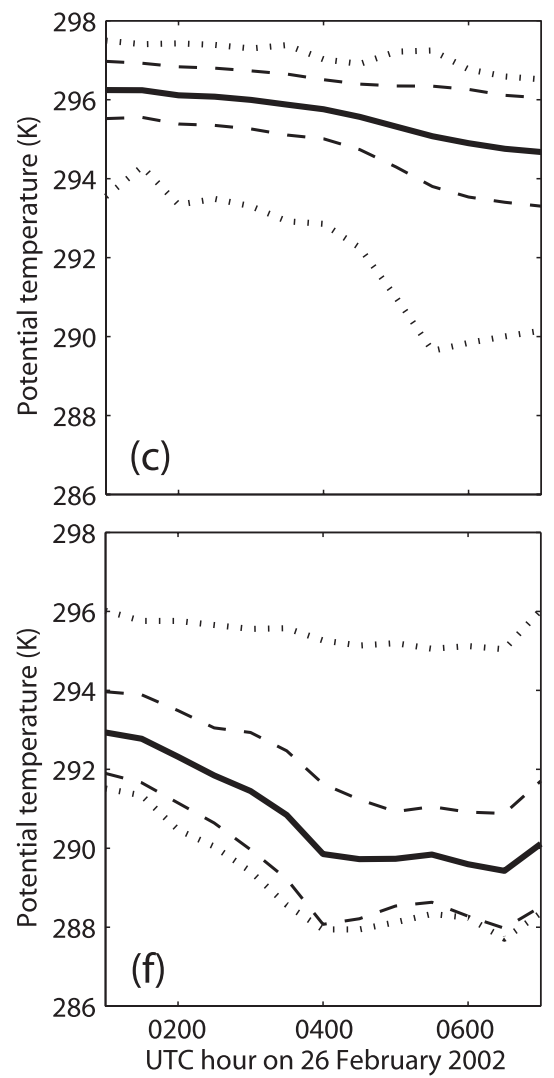

FIG. 13. As in Fig. 12, but for (a),(d) RH with respect to ice; (b),(e) $q$; and (c),(f) $\theta$.

the sting-jet acceleration is due to the environmental geostrophic wind increasing in strength. However, analysis of the evolution of the geostrophic wind along trajectories (not shown in figures) shows that (i) sting-jet horizontal velocity and geostrophic velocity have a maximum deviation of less than $45^{\circ}$ throughout the descent, (ii) during the first $2.5 \mathrm{~h}$ of descent (until approximately 0330 UTC) the maximum deviation between sting-jet horizontal velocity and geostrophic velocity is less than $20^{\circ}$, (iii) geostrophic wind remains fairly constant for the first $4 \mathrm{~h}$ of descent (until approximately 0500 UTC), and (iv) sting-jet wind, on the other hand, is supergeostrophic and accelerating during these first $4 \mathrm{~h}$. These four facts indicate that the acceleration during the early descent is due to processes other than the synoptic deepening of the cyclone. This does not mean that the sting-jet acceleration and the increase in geostrophic wind are not related. Indeed, the same trajectory analysis of geostrophic winds shows that this might be true for the last $2 \mathrm{~h}$ of descent. Nevertheless, further research is needed to clarify this relationship.

In the following two subsections the evidence for the occurrence of two processes that can be responsible for the sting jet acceleration, namely evaporative cooling and the release of CSI, is investigated.

\section{1) Evaporative COOLING}

In the MetUM, mean $\mathrm{RH}$ decreases steadily from about $85 \%$ to less than $40 \%$ along sting-jet trajectories (Fig. 13a). In contrast, in the COSMO model RH remains nearly constant for most of the period of analysis, sharply decreasing at the end of the trajectories to less than $80 \%$ (Fig. 13d). These changes in RH can be explained by looking at changes in specific humidity and potential temperature. Unlike the case studied by Clark et al. (2005), where there was no significant change in mean potential temperature and specific humidity along the trajectories, in this case mean changes of these two variables along the trajectories are apparent. In the MetUM, specific humidity increases on average about $0.4 \mathrm{~g} \mathrm{~kg}^{-1}$ (Fig. 13b) and potential temperature decreases on average by approximately $1.5 \mathrm{~K}$ (Fig. 13c) during the period of analysis. In the COSMO model mean specific humidity increases by $1.0 \mathrm{~g} \mathrm{~kg}^{-1}$ from 0100 to 0400 UTC (Fig. 13e); during the same interval, mean potential temperature decreases by around $3 \mathrm{~K}$ (Fig. 13f). From 0400 UTC onward, both specific humidity and potential temperature remain fairly constant, allowing a decrease in $\mathrm{RH}$. These results can be explained by assuming 

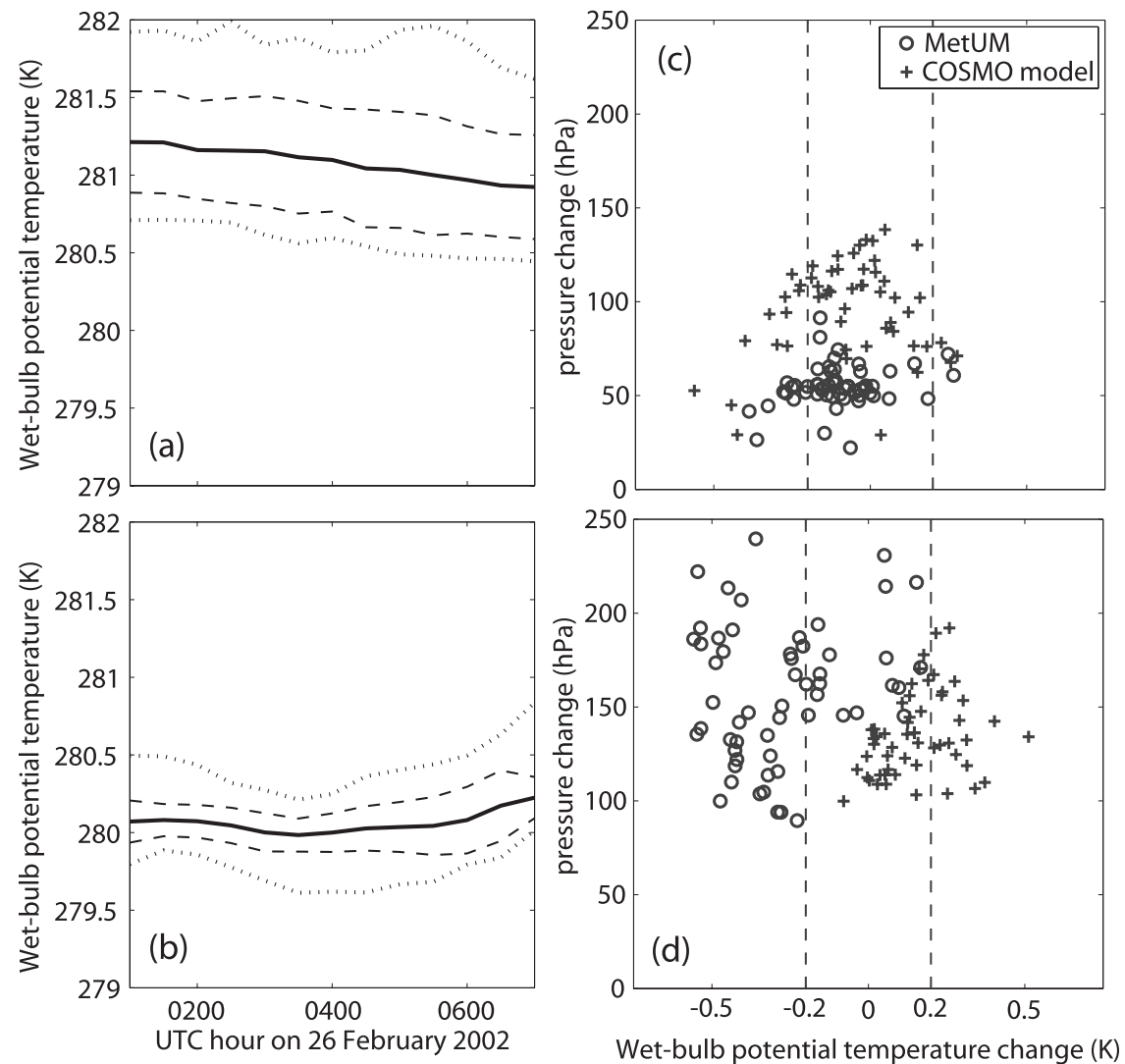

FIG. 14. Time series along the trajectories of $\theta_{w}$ for (a) the MetUM and (b) the COSMO model, showing mean values (solid), mean values $\pm 1 \sigma$ (dashed) and instantaneous maxima and minima (dotted). Change in pressure against total change in $\theta_{w}$ along trajectories in the MetUM and the COSMO model between the start of descent at 0100 UTC and (c) 0400 and (d) 0700 UTC.

cooling due to evaporation of rain and snow falling into the parcel ensemble from upper levels, taking place during the descent. However, this process did not occur in the same way in both models. In the MetUM, the first half of the trajectory (until approximately 0400 UTC) is nearly dry adiabatic, with a more noticeable increase in specific humidity from 0400 UTC onward. In contrast, COSMO model trajectories show a sharp increase in specific humidity to maintain a nearly saturated state, possibly indicating that sting jet air remained cloudy as it descended, at least until 0400 UTC. Other processes, such as mixing, could also be an explanation for the cooling effect. However, given that the sting jet air is descending, it can be assumed to have an at least slightly lower temperature than its surroundings. Under this assumption, the sting jet air would be expected to warm up rather than cool down if mixing was the main active process.

To further investigate the occurrence of evaporative cooling, we can look at the evolution of $\theta_{w}$. By construction, $\theta_{w}$ along trajectories is conserved within a $2-\mathrm{K}$ band. Nevertheless, there are small variations that can be seen in Figs. 14a,b. In the MetUM $\theta_{w}$ decreases along trajectories by about $0.3 \mathrm{~K}$ in total, whereas in the COSMO model there is a very slight decrease from 0100 to 0400 UTC, followed by an increase until 0700 UTC. These processes can be seen more clearly in Figs. 14c,d, which show change in pressure against change in $\theta_{w}$ at 0400 and 0700 UTC. To interpret these figures, we arbitrarily define a moist pseudoadiabatic process as one whose change in $\theta_{w}$ remains in a band between -0.2 and $0.2 \mathrm{~K}$. Thus, by 0400 UTC MetUM trajectories have descended around $50 \mathrm{hPa}$ conserving $\theta_{w}$, albeit with a slight negative deviation from the moist pseudoadiabatic zone. On the other hand, COSMO model trajectories show a descent by about $100 \mathrm{hPa}$ with a greater negative deviation from the moist pseudoadiabatic zone. At 0700 UTC the picture is different. Having descended an average of $150 \mathrm{hPa}$, MetUM trajectories show a clear negative deviation from the moist pseudoadiabatic zone, whereas COSMO model trajectories show now a positive deviation. The decrease in $\theta_{w}$ along trajectories, from 0100 to 0400 UTC in the COSMO model, and over the 

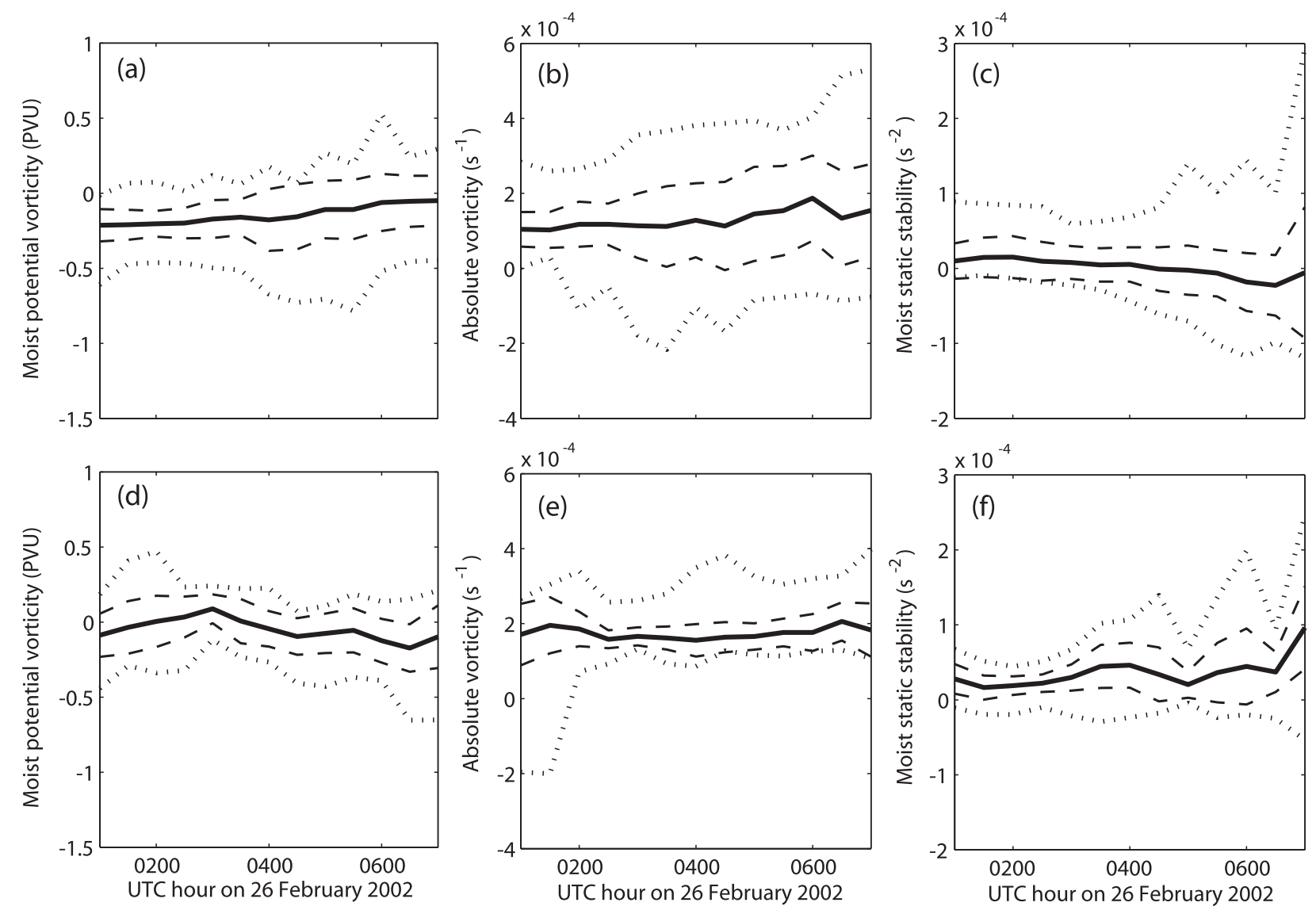

FIG. 15. As in Fig. 12, but for (a),(d) MPV; (b),(e) $\zeta_{a}$; and (c),(f) $N_{m}^{2}$.

whole descent in the MetUM, is qualitatively consistent with descent in the presence of ice processes (see, e.g., Bohren and Albrecht 1998). Therefore, the occurrence of ice processes is a likely explanation for the slight moist potential cooling along trajectories. The slight increase at the end of the trajectory in the COSMO model could be due to mixing, as the sting jet enters the boundary layer. (Note that the sting jet descends lower in the COSMO model and is, hence, more likely to be subject to mixing within the boundary layer.)

\section{2) RELEASE OF CSI}

Another feature that shows consistency between the MetUM and the COSMO model is the predominantly negative values of MPV along the trajectories. This variable is negative on average over the entire time period in the MetUM, with $100 \%$ of the trajectories having negative MPV at 0100 UTC decreasing to $53 \%$ at 0700 UTC (Fig. 15a). In the COSMO model, MPV starts with a negative mean value. Then, it increases, reaching a positive maximum at 0300 UTC before decreasing to become negative again at 0330 UTC (Fig. 15d). Despite this variation, a significant proportion of the trajectories bear negative values.

Absolute vorticity $\zeta_{a}(=f+\zeta$, where $f=2 \Omega \sin \phi$ is the Coriolis parameter, $\Omega$ is the earth's rotation rate, $\phi$ is latitude, and $\zeta$ is relative vorticity) and moist static stability were also computed along backward trajectories to assess the potential role of CSI release (Fig. 15). For this purpose, moist static stability was computed as [based on Durran and Klemp (1982)]

$$
N_{m}^{2}=\frac{g}{T}\left(\frac{\partial T}{\partial z}+\Gamma_{m}\right)\left(1+\frac{L r_{s}}{R T}\right)-\frac{g}{1+q} \frac{\partial q}{\partial z}
$$

with the moist adiabatic lapse rate given by

$$
\Gamma_{m}=\frac{g}{c_{p}}\left(\frac{1+\frac{L r_{s}}{R T}}{1+\frac{L^{2} r_{s}}{R_{v} T^{2} c_{p}}}\right),
$$

where $T$ is temperature; $q$ is specific humidity; $r_{s}$ is the saturation mixing ratio; $L$ is the latent heat of vaporization; 
and $R, R_{v}$, and $c_{p}$ are the dry and moist air gas constants and specific heat capacity at constant pressure, respectively. Here $N_{m}^{2}$ is a measure of the gravitational stability of a saturated atmosphere. Absolute vorticity was found to be characterized by positive mean values throughout the interval in both models (Figs. 15b,e). In the MetUM, $N_{m}^{2}$ was found to be positive on average between 0100 and 0400 UTC, with $47 \%$ of the parcels bearing positive values at 0100 UTC (Fig. 15c). Following individual trajectories within the ensemble, it was found that the percentage of parcels characterized by negative MPV and positive $\zeta_{a}$ and $N_{m}^{2}$ oscillates around $45 \%$ until 0430 UTC when it decreases to about $20 \%$. In the COSMO model, $N_{m}^{2}$ is positive on average throughout the time period, with more than $80 \%$ of the parcels having positive moist static stability at any time (Fig. 15f). In this model, the percentage of parcels characterized by negative MPV and positive $\zeta_{a}$ and $N_{m}^{2}$ oscillates between $70 \%$ and $40 \%$, with just a sharp depression around 0300 UTC when it decreases to $10 \%$.

These results can be interpreted in the light of CSI theory (Bennetts and Hoskins 1979; Schultz and Schumacher 1999), according to which unstable atmospheric regions are characterized by negative MPV in saturated air in the absence of conditional and inertial instabilities, as indicated by positive values of $N_{m}^{2}$ and $\zeta_{a}$. Thus, at least $47 \%(65 \%)$ of the trajectories that constitute the sting jet in the MetUM (COSMO model) are seemingly descending from a region in the midtroposphere that is conditionally symmetrically unstable, and the release of this instability could be a major cause of the occurrence of the sting jet. This would be valid at the start of the trajectories (0100 UTC), when the air is saturated, satisfying the conditions assumed by CSI theory. Assessing the situation at later times in the MetUM output (when sting-jet air has started to dry out while descending) becomes more complex. It is sensible to expect a certain degree of instability remaining during the first stages of descent, even under conditions of partial saturation. Moreover, other processes, such as evaporative cooling, could enhance the descent (as previously discussed). Once the instability has been fully released, a downward overshoot could be expected since the air would have gained momentum (analogous to vertically ascending air in a cloud overshooting the level of neutral buoyancy). However, these ideas should be subject to further examination.

\section{Summary and conclusions}

The Met Office's MetUM and the COSMO model have been used in a new case study of a sting-jet storm. The comparison between these two models has revealed insights into the processes that are involved in the development of the sting jets within this storm. The simulations were validated by comparison with Met Office operational synoptic analyses (ASXX charts), ECMWF operational analyses and satellite imagery, as well as surface observations of mean winds and wind gusts. The simulated cyclones reasonably resemble the observed cyclone. However, it must be noted that discrepancies in position and central pressure between the Met Office and the ECMWF analyses were found. These discrepancies highlight limitations of operational NWP models (and analyses) in dealing with and predicting rapidly developing cyclonic systems.

A method for the search of sting jets in the highresolution output from the models has been introduced. This method is based on the clustering of neighboring grid points that satisfy certain criteria chosen based on the findings of Clark et al. (2005). These criteria were designed to identify low-level regions of dry, descending air with strong horizontal wind speed located within the frontal-fracture zone. Once the clusters were identified, backward trajectories were used to investigate the origin and evolution of air parcels in the clusters. When this analysis revealed that the air parcels descended from a cloudy region remaining within representative $\theta_{w}$ values of the frontal-fracture region, then the cluster was labeled as a sting jet.

Both models have simulated a sting jet as defined by these criteria. These simulations shared three major characteristics that can then be considered as robust features of this sting-jet case in two separate mesoscale simulations. First, the location of the sting jet and the evolution of the ensemble of trajectories are strikingly similar in both models. Moreover, the frontal-fracture region in both models exhibits similar structure. Second, both models show evaporative cooling during the descent of the airstream constituting the sting jet; the analysis of backward trajectories along the identified sting jets shows that during the descent a gain in specific humidity takes place while potential temperature decreases. Third, the presence of negative MPV (and positive $N_{m}^{2}$ and $\zeta_{a}$ ) in the region of initial descent in both models suggests that the release of conditional symmetric instability could be a driver for the initiation of the sting jet.

Even with all these similarities, the simulated sting jets were not identical. The sting jet in the COSMO model evolved at lower altitude and lower $\theta_{w}$ than that in the MetUM. Furthermore, it showed stronger signs of evaporative cooling taking place along its trajectory than the MetUM sting jet. A comparison of the evolution of MPV along trajectories in the models shows that the release of CSI possibly took place at different rates and, perhaps, at different stages. An additional difference between the models was that the COSMO model forecast 
produced a second later jet with sting-jet characteristics whereas the MetUM did not exhibit signs of the presence of this event. The second sting jet occurred about $4 \mathrm{~h}$ later than the sting jet reproduced by both models (and analyzed here). However, given the lack of active data assimilation [other than the information given by the initial conditions (in both models) and the LBCs (in the COSMO model)], the difference between the models in this respect could be due to the natural divergence in the solution due to the nonlinearity of the system.

Given the very few cases previously studied on the subject, a central contribution of this article is that it provides further evidence, from one new case, for the occurrence of sting jets in at least some rapidly deepening extratropical cyclones with frontal fracture [cyclones developing according to the model of Shapiro and Keyser (1990)]. Moreover, it presents evidence that supports the current conceptual model of sting jets (Clark et al. 2005). However, it also shows that sting jets do not necessarily reach the surface or the top of the boundary layer. In particular, the MetUM simulation showed the presence of low-level frontal circulations preventing the descending jet from reaching levels below $800 \mathrm{hPa}$. Thus, an aspect of the development of sting jets that awaits deeper understanding is those processes taking place once the sting jet approaches the boundary layer. There is one observational study that shows that the generation of boundary layer convergence lines once sting-jet air reaches the top of the boundary layer is the cause of certain arc-shaped and chevron-shaped clouds within the dry slot (Browning and Field 2004). However, work is needed to clarify, for example, the influence of the boundary layer stability in the mass and momentum transfer from the top of the boundary layer to the surface [an issue also identified in Clark et al. (2005)]. This is a central question given that sting jets' damage potential is precisely due to the possibility of high momentum air reaching the surface. Furthermore, although evidence for the release of CSI has been presented in this study, there are still aspects of this mechanism in relation to the phenomenology of sting jets that need to be clarified by further studies. In particular, the release of CSI from upper-level (as opposed to lower level) unstable regions is not fully understood. Finally, one further aspect of critical practical importance is the frequency in occurrence and intensity as well as the spatial distribution of these phenomena, for which the construction of a climatology of sting jets would be desirable. Such a study (currently being undertaken by authors O. MartínezAlvarado and S. L. Gray) would be of value not only for the scientific meteorological community but also for other parties such as policy makers and the insurance industry.
Acknowledgments. We thank the Met Office for making the MetUM available, the DWD for providing the COSMO model, and the National Centre for Atmospheric Sciences (NCAS) Computational Modelling Support (CMS) for providing computing and technical support. We also thank Dr. Graham Parton for his suggestion for the case study, and Prof. Peter Clark for the useful and extensive discussions on the results here presented. This work has been funded by the (United Kingdom) Natural Environment Research Council (NERC) through Grant NE/E004415/1. The contribution from FW has been funded by the German Research Foundation (DFG) as part of the Collaborative Research Center 671 "Tropospheric ice phase." We thank the three anonymous reviewers and the editor D. Schultz for their insightful suggestions that helped to bring this article to an improved final form.

\section{REFERENCES}

Baker, L., 2009: Sting jets in severe northern European wind storms. Weather, 64, 143-148.

Bennetts, D. A., and B. J. Hoskins, 1979: Conditional symmetric instability-A possible explanation for frontal rainbands. Quart. J. Roy. Meteor. Soc., 105, 945-962.

Bjerknes, J., 1919: On the structure of moving cyclones. Geofys. Publ., 1 (2), 1-8.

— , and H. Solberg, 1922: Life cycle of cyclones and the polar front theory of atmospheric circulation. Geofys. Publ., 3 (1), 3-18.

Bohren, C. F., and B. A. Albrecht, 1998: Atmospheric Thermodynamics. Oxford University Press, $402 \mathrm{pp}$.

Browning, K. A., 2004: The sting at the end of the tail: Damaging winds associated with extratropical cyclones. Quart. J. Roy. Meteor. Soc., 130, 375-399.

_ analysis of cold fronts. Quart. J. Roy. Meteor. Soc., 108, 435-452.

— , and M. Field, 2004: Evidence from Meteosat imagery of the interaction of sting jets with the boundary layer. Meteor. Appl., 11, 277-289.

— S. P. Ballard, and C. S. A. Davitt, 1997: High-resolution analysis of frontal fracture. Mon. Wea. Rev., 125, 1212-1230.

Carlson, T. N., 1980: Airflow through midlatitude cyclones and the comma cloud pattern. Mon. Wea. Rev., 108, 1498-1509.

Clark, P. A., K. A. Browning, and C. Wang, 2005: The sting at the end of the tail: Model diagnostics of fine-scale threedimensional structure of the cloud head. Quart. J. Roy. Meteor. Soc., 131, 2263-2292.

Davies, T., M. J. P. Cullen, A. J. Malcolm, M. H. Mawson, A. Staniforth, A. A. White, and N. Wood, 2005: A new dynamical core for the Met Office's global and regional modelling of the atmosphere. Quart. J. Roy. Meteor. Soc., 131, 1759-1782.

Dominy, P., 2006: Creating the daily analysis charts for the Weather log. Weather, 61, 167-170.

Doms, G., and Coauthors, 2007: A description of the nonhydrostatic regional model LM. Part II: Physical parameterization. Tech. Rep. LM_F90 3.20, Consortium for Small-Scale 
Modelling, 146 pp. [Available online at http://www.cosmomodel.org.]

Durran, D. R., and J. B. Klemp, 1982: On the effects of moisture on the Brunt-Väisälä frequency. J. Atmos. Sci., 39, 2152-2158.

Edwards, J., and A. Slingo, 1996: Studies with a flexible new radiation code. Part I: Choosing a configuration for a large-scale model. Quart. J. Roy. Meteor. Soc., 122, 689-719.

Gray, S. L., and A. J. Thorpe, 2001: Parcel theory in three dimensions and the calculation of SCAPE. Mon. Wea. Rev., 129, $1656-1672$.

Gregory, D., and P. R. Rowntree, 1990: A mass flux convection scheme with representation of cloud ensemble characteristics and stability-dependent closure. Mon. Wea. Rev., 118, 14831506.

Grønås, S., 1995: The seclusion intensification of the New Year's Day storm 1992. Tellus, 47A, 733-746.

Keller, J. L., P. S. Dailey, and M. D. Fischer, 2004: A statisticaldynamical model for quantifying regional storm climates. Preprints, 14th Conf. on Applied Climatology, Seattle, WA, Amer. Meteor. Soc., 5.1. [Available online at http://ams. confex.com/ams/pdfpapers/69267.pdf.]

Lock, A. P., A. R. Brown, M. R. Bush, G. M. Martin, and R. N. B. Smith, 2000: A new boundary layer mixing scheme. Part I: Scheme description and single-column model tests. Mon. Wea. Rev., 128, 3187-3199.

Louis, J.-F., 1979: A parametric model of vertical eddy fluxes in the atmosphere. Bound.-Layer Meteor., 17, 187-202.

Marshall, J. S., and W. M. Palmer, 1948: The distribution of raindrops with size. J. Meteor., 5, 165-166.

Mellor, G., and T. Yamada, 1982: Development of a turbulence closure model for geophysical fluid problems. Rev. Geophys. Space Phys., 20, 851-875.

Novak, D. R., L. F. Bosart, D. Keyser, and J. S. Waldstreicher, 2004: An observational study of cold season-banded precipitation in northeast U.S. cyclones. Wea. Forecasting, 19, 993-1010

_ J. S. Waldstreicher, D. Keyser, and L. F. Bosart, 2006: A forecast strategy for anticipating cold season mesoscale band formation within eastern U.S. cyclones. Wea. Forecasting, 21, $3-23$.

— , B. A. Colle, and S. E. Yuter, 2008: High-resolution observations and model simulations of the life cycle of an intense mesoscale snowband over the northeastern United States. Mon. Wea. Rev., 136, 1433-1456.

Panofsky, H. A., and J. A. Dutton, 1984: Atmospheric Turbulence: Models and Methods for Engineering Applications. John Wiley, $418 \mathrm{pp}$.

, H. Tennekes, D. H. Lenschow, and J. C. Wyngaard, 1977: The characteristics of turbulent velocity components in the surface layer under convective conditions. Bound.-Layer Meteor., 11, 355-361.

Parton, G. A., G. Vaughan, E. G. Norton, K. A. Browning, and P. A. Clark, 2009: Wind profiler observations of a sting jet. Quart. J. Roy. Meteor. Soc., 135, 663-680.

—, A. Dore, and G. Vaughan, 2010: A climatology of midtropospheric mesoscale strong wind events as observed by the MST radar, Aberystwyth. Meteor. Appl., 17, 340-354, doi:10.1002/met.203.

Persson, P. O. G., and T. T. Warner, 1991: Model generation of spurious gravity waves due to inconsistency of the vertical and horizontal resolution. Mon. Wea. Rev., 119, 917-935.

$\longrightarrow$, and _ 1993: Nonlinear hydrostatic conditional symmetric instability: Implications for numerical weather prediction. Mon. Wea. Rev., 121, 1821-1833.

Ritter, B., and J.-F. Geleyn, 1992: A comprehensive radiation scheme for numerical weather prediction models with potential applications in climate simulations. Mon. Wea. Rev., 120, 303-325.

Sanders, F., and J. R. Gyakum, 1980: Synoptic-dynamic climatology of the "bomb." Mon. Wea. Rev., 108, 1589-1606.

Schultz, D. M., 2001: Reexamining the cold conveyor belt. Mon. Wea. Rev., 129, 2205-2225.

— tional symmetric instability. Mon. Wea. Rev., 127, 2709-2732.

_ genesis in a conditionally, symmetrically, and inertially unstable environment. Mon. Wea. Rev., 135, 2095-2110.

— - D. Keyser, and L. F. Bosart, 1998: The effect of large-scale flow on low-level frontal structure and evolution in midlatitude cyclones. Mon. Wea. Rev., 126, 1767-1791.

Schulz, J. P., 2008: Revision of the turbulent gust diagnostics in the COSMO model. COSMO Newsl., 8, 17-22.

Shapiro, M. A., and D. Keyser, 1990: Fronts, jet streams and the tropopause. Extratropical Cyclones: The Erik Palmén Memorial Volume, C. W. Newton and E. O. Holopainen, Eds., Amer. Meteor. Soc., 167-191.

Skamarock, W. C., and J. B. Klemp, 1992: The stability of time-split numerical methods for the hydrostatic and nonhydrostatic elastic equations. Mon. Wea. Rev., 120, 2109-2127.

Tiedke, M., 1989: A comprehensive mass flux scheme for cumulus parameterization in large-scale models. Mon. Wea. Rev., 117, 1779-1799.

Vaughan, G., 2002: The UK MST Radar. Weather, 57, 69-73.

Wernli, H., and H. C. Davies, 1997: A Lagrangian-based analysis of extratropical cyclones. I: The method and some applications. Quart. J. Roy. Meteor. Soc., 123, 467-489.

Wilson, D. R., and S. P. Ballard, 1999: A microphysically based precipitation scheme for the UK Meteorological Office Unified Model. Quart. J. Roy. Meteor. Soc., 125, 1607-1636. 